\title{
The microbiome and autoimmunity: a paradigm from the gut-liver axis
}

\author{
Bo Li ${ }^{1}$, Carlo Selmi ${ }^{2,3}$, Ruqi Tang ${ }^{1}, \mathrm{ME} \mathrm{Gershwin}{ }^{4}$ and Xiong $\mathrm{Ma}^{1}$
}

Microbial cells significantly outnumber human cells in the body, and the microbial flora at mucosal sites are shaped by environmental factors and, less intuitively, act on host immune responses, as demonstrated by experimental data in germ-free and gnotobiotic studies. Our understanding of this link stems from the established connection between infectious bacteria and immune tolerance breakdown, as observed in rheumatic fever triggered by Streptococci via molecular mimicry, epitope spread and bystander effects. The availability of high-throughput techniques has significantly advanced our capacity to sequence the microbiome and demonstrated variable degrees of dysbiosis in numerous autoimmune diseases, including rheumatoid arthritis, type 1 diabetes, multiple sclerosis and autoimmune liver disease. It remains unknown whether the observed differences are related to the disease pathogenesis or follow the therapeutic and inflammatory changes and are thus mere epiphenomena. In fact, there are only limited data on the molecular mechanisms linking the microbiota to autoimmunity, and microbial therapeutics is being investigated to prevent or halt autoimmune diseases. As a putative mechanism, it is of particular interest that the apoptosis of intestinal epithelial cells in response to microbial stimuli enables the presentation of self-antigens, giving rise to the differentiation of autoreactive Th17 cells and other T helper cells. This comprehensive review will illustrate the data demonstrating the crosstalk between intestinal microbiome and host innate and adaptive immunity, with an emphasis on how dysbiosis may influence systemic autoimmunity. In particular, a gut-liver axis involving the intestinal microbiome and hepatic autoimmunity is elucidated as a paradigm, considering its anatomic and physiological connections.

Cellular and Molecular Immunology advance online publication, 30 April 2018; doi:10.1038/cmi.2018.7

Keywords: autoimmunity; autoimmune liver disease; dysbiosis; microbiome

\section{INTRODUCTION}

The incidence of autoimmune and inflammatory diseases has been increasing worldwide, along with an earlier diagnosis and increased physician awareness. More importantly, changes in environmental factors, such as a modern lifestyle, dietary habits, antibiotic use and hygiene, are hypothesized to have a critical role, ${ }^{1}$ as ideally represented by the largely incomplete concordance in autoimmune and chronic inflammatory diseases observed in monozygotic twins, ${ }^{2}$ in whom differences in the gut microbiome have also been emphasized. ${ }^{3,4}$ Indeed, human intestinal mucosal sites represent the sites that are most influenced by the surrounding environment, and millions of microbial residents have emerged as a unique organ that constantly shapes host immunity and metabolism. Recently, perturbed microbial composition and function, termed 'dysbiosis', has been associated with autoimmune diseases, particularly, rheumatoid arthritis (RA), type 1 diabetes (T1D), multiple sclerosis (MS) and autoimmune liver disease (AILD). Manipulation of germ-free and gnotobiotic animal models also sheds some light on how specific changes in the microbiome affect host autoimmunity. ${ }^{5}$

The mechanistic links between the microbiome and autoimmune diseases remain largely unknown. It seems plausible to draw an analogy from how infectious bacteria disrupt immune

\footnotetext{
${ }^{1}$ Division of Gastroenterology and Hepatology, Key Laboratory of Gastroenterology and Hepatology, Ministry of Health, State Key Laboratory for Oncogenes and Related Genes, Renji Hospital, School of Medicine, Shanghai Jiao Tong University, Shanghai Institute of Digestive Disease, Shanghai 200001, China; ${ }^{2}$ Division of Rheumatology and Clinical Immunology, Humanitas Research Hospital, Rozzano, Italy; ${ }^{3}$ BIOMETRA Department, University of Milan Milan, Italy and ${ }^{4}$ Division of Rheumatology, Department of Medicine, Allergy and Clinical Immunology, University of California at Davis, Davis, CA, USA

Correspondence: Dr X Ma, MD, Division of Gastroenterology and Hepatology, Key Laboratory of Gastroenterology and Hepatology, Ministry of Health, State Key Laboratory for Oncogenes and Related Genes, Renji Hospital, School of Medicine, Shanghai Jiao Tong University, Shanghai Institute of Digestive Disease, 145 Middle Shandong Road, Shanghai 200001, China.
}

E-mail: maxiongmd@hotmail.com

Received: 20 October 2017; Revised: 1 January 2018; Accepted: 2 January 2018 
tolerance (for example, rheumatic fever triggered by Streptococci), such as molecular mimicry, epitope spread and bystander effects. ${ }^{6-8}$ Indeed, it has been demonstrated that apoptosis of intestinal epithelial cells in response to microbial infection enables the presentation of self-antigens, resulting in differentiation of autoreactive Th17 cells and other T helper cells. ${ }^{9}$ By using a spontaneous model of autoimmune uveitis, Horai et al. ${ }^{10}$ have elegantly demonstrated that retina-specific $\mathrm{T}$ cells are first activated in the intestine by commensal microbes and subsequently evoke autoimmune attack in the immuneprivileged eye site. In addition, a recent study involving three infant cohorts showed that children from districts with a higher prevalence of autoimmune diseases are dominated by bacterial species that produce less immunogenic lipopolysaccharide $(\text { LPS })^{11}$ and that different microbiome-derived LPSs display different structures and immunogenic functions, which may influence early-life immunological education and account for the variable autoimmune disease predisposition among individuals. ${ }^{11}$ One may speculate that the associations between commensal microbiome and host autoimmunity are rather complex and multifactorial. Apparently, harnessing the intestinal microbiome to control and prevent autoimmune diseases or using this information to diagnose and stratify patients still requires a more comprehensive characterization of the diseaserelated microbiome and a deeper understanding of its causality.

Thus, this review will first provide a basic overview of the interactions between the intestinal microbiome and the immune system, with an emphasis on how these interactions affect host autoimmunity locally and systemically, which might underlie the human microbiome studies described in this article. In particular, a gut-liver axis involving intestinal microbiome and autoimmune liver diseases will be elucidated separately, given the special anatomic and physiological relationships of liver, intestine and its microbial contents. We will not discuss the bacterial species observed in other sites, such as the skin or genitalia.

\section{The gut microbiome and immunity}

Mounting evidence points towards a potential involvement of immune dysregulation at mucosal sites during the initiation and progression of autoimmune diseases. One hypothesis is that in the settings of intestinal inflammation, impairment of the gut barrier results in bacterial translocation, which then stimulates immune reactions in distant organs. Alternatively, immune cells are abnormally skewed by dysbiosis, as observed for Th17 polarization. Indeed, Th17 cells are most abundant in the lamina propria of the intestine, where they secrete the proinflammatory cytokines interleukin (IL)-17A, IL-17F and IL-22 to enforce gut barrier integrity and defense against pathogens. ${ }^{12}$ It is now widely accepted that understanding the complex interactions between the microbiome and immune system will be crucial to defining and treating or reversing the pathogenesis of chronic autoimmune diseases.

Interaction between the microbiome and innate immunity. Innate immune cells are strategically distributed at the hostmicrobiome interface at mucosal sites and constitute the first line to sense the components or products of microorganisms and to transduce signals into the host, eliciting responses that may in turn alter the composition and function of the microbiome. ${ }^{5}$ Dysbiosis has been observed in several mouse models of innate immune deficiency, including mice that lack the genes MyD88, ${ }^{13}$ Toll-like receptor 5 (TLR5) ${ }^{14}$ and nucleotide-binding oligomerization domain-containing protein 2 (NOD2). ${ }^{15,16}$ TLRs and NOD-like receptors (NLRs) are both pattern recognition receptors (PRRs) by which the host senses conserved components of the microbiome. The absence of these innate immune receptors undermines defense against pathogens, predisposing the tissue to spontaneous inflammation. For instance, mice that are deficient in TLR5 develop features of metabolic syndrome correlated with an altered microbiome. ${ }^{14}$ The absence of NOD2, an intracellular PRR for bacterial peptidoglycans, elicits transmissible colitis and colitisassociated carcinogenesis in mice, possibly due to an impaired restriction of Bacteroides vulgatus. ${ }^{15,17}$

Recent studies have revealed a central role of the inflammasome pathway and interleukin-18 (IL-18) in orchestrating host-microbial crosstalk. Inflammasomes are multi-protein complexes consisting of NLR proteins, ASC and caspase-1. Once assembled, inflammasomes become activated via autocleavage of pro-caspase-1, which then processes IL- $1 \beta$ and IL-18. Levy et al. ${ }^{18}$ revealed that the microbiome-associated metabolites taurine, histamine and spermine can induce NLRP6 inflammasome activation, IL-18 production and subsequent anti-microbial peptide (AMP) generation, which is key for the integrity of the gut barrier and commensal colonization. This inflammasome modulation by the microbiome has recently been confirmed by the discovery that intestinal colonization with the protozoan Tritrichomonas musculis also activates the epithelial inflammasome to release IL-18, which promotes Th1 and Th17 immunity driven by dendritic cells. ${ }^{19}$

In addition to phagocytosis, the formation of neutrophil extracellular traps (NETs), a web-like DNA structure with numerous anti-microbial proteins and proteolytic enzymes, is another process that enables neutrophil to capture and eradicate bacteria. Emerging evidence has indicated that NETs are associated with noninfectious pathologic conditions, including the autoimmune diseases RA and systemic lupus erythematosus (SLE). ${ }^{20-22}$ Moreover, the interaction between NETs and dysbiosis in the setting of inflammatory and autoimmune diseases has been of particular interest. Vong et al. ${ }^{23}$ reported the differential capacity of intestinal microbes to elicit NETs. Accordingly, the probiotic Lactobacillus spp. dampen the ability of neutrophils to form NETs, whereas enteropathogenic E. coli exhibit an increased capacity to mobilize the neutrophil oxidative burst and activate NETs, suggesting an innate connection between dysbiosis and neutrophil function. ${ }^{24,25}$ In addition, NETs have been associated with sites beyond the intestine, such as RA-related autoimmunity in the lungs. ${ }^{21}$ The frequency of NET complexes is correlated with the sputum microbial diversity and an impaired capacity for neutrophil phagocytosis of bacteria in patients with 
chronic obstructive pulmonary disease (COPD). ${ }^{25}$ Whether the dominance of NETs precedes the disturbance of mucosal microbiota or the pathogenic microbes elicit excessive NET production and how they interact to initiate and maintain the chronic inflammation require further investigation.

Except for the general recognition of bacteria by PRRs, the microbiome can signal through metabolites and affects host transcription in the intestine or in distal organs. ${ }^{26}$ Indeed, short-chain fatty acids (SCFAs), the major fermentation products that are generated from commensal microbiome degrading dietary fiber, are capable of regulating cell functions either by modification of histone deacetylase (HDAC) ${ }^{27}$ or by activation of 'metabolite-sensing' G-protein-coupled receptors (GPCRs) ${ }^{28}$ For example, SCFAs derived from a high-fiber diet protect mice against colitis by binding to GPR43 and GPR109 on colonic epithelium cells, which leads to NLRP3 inflammasome activation and IL-18 release. ${ }^{29}$ Deprivation of dietary fiber renders the gut microbiome mucus-degrading, which further enhances mucosal susceptibility to the pathogen Citrobacter rodentium. ${ }^{30}$ In addition to SCFAs, catabolism of the amino acid tryptophan to indole derivatives by commensal bacteria is also well positioned to balance gut homeostasis. Zelante et al. ${ }^{31}$ have shown that a subset of Lactobacilli utilizes tryptophan to produce indole-3-aldehyde (IAID), which then acts as a ligand of aryl hydrocarbon receptor (AHR). Activation of AHR on innate lymphoid cells (ILCs) promotes its production of IL-22 and thus provides colonization resistance to Candida albicans. Manipulation of the feedback control of AHR signaling cytochrome P4501 (CYP1) enzymes results in a loss of AHR-dependent ILC3 and Th17 cells, which can be reversed by supplementation of AHR ligands in the diet. ${ }^{32}$ Recently, impaired tryptophan metabolism by the microbiome due to a deficiency in the CARD-9 gene has also been associated with susceptibility to colonic inflammation. ${ }^{33}$ Other metabolites, such as inosine, may be remodeled by Lactobacillus reuteri, which then suppress the autoimmunity caused by Treg deficiency. ${ }^{34}$

Thus, the interactions between microorganisms and the host extend well beyond classic immune cells. ILCs are a newly discovered arm of the innate immune system that are enriched at mucosal sites, and the ILC3 subset is characterized by ROR $\gamma \mathrm{t}$ expression and is most related to the commensal microbiome. Intestinal lymphoid tissue colonization by commensal bacteria is beneficial for host-microbial mutualism, mainly by inducing DC-derived IL-10 and group 3 ILC-derived IL-22. ${ }^{35}$ However, depletion of ILCs results in a defective containment of these commensal bacteria and promotes systemic inflammation. ${ }^{36}$ IL-22 secreted by ILC3 has received particular attention in gut homeostasis because of its pleiotropic roles in AMP release, mucus production, intestinal epithelial regeneration and colonization resistance to pathogens. ${ }^{31,37}$ Moreover, lymphotoxin (LT) $-\alpha$ and LT- $\beta$ expressed by ILC3s contribute to T celldependent and T cell-independent IgA induction. ${ }^{38}$ In contrast, the dynamics of the intestinal microbiome have been suggested to impact the epigenetic regulation and gene expression of ILC. ${ }^{39}$ Flagellin sensed by CD103+ myeloid cells promotes the production of IL-22 by ILCs through IL-23. ${ }^{40}$ Upon microbial recognition, IL-1 $\beta$ produced by intestinal macrophage drives granulocyte-macrophage colony-stimulating factor secretion by ILC3, which then acts on DCs to adjust intestinal $\mathrm{T}$ cell tolerance to commensals. ${ }^{41}$ However, instead of conventional CD103+ dendritic cells (cDCs), Longman et al. ${ }^{42}$ showed that monocyte-derived CX3CR1+ cells are more efficient in providing IL-23 and IL-1 $\beta$, thus supporting IL-22 production by ILC3. Intriguingly, it has recently been proposed that ILC3s expressing class II MHC can induce apoptosis of commensal microbiome-reactive CD4+ T cells. ${ }^{43}$ Similar to medullary thymic epithelial cells, ILC3 presents commensal antigens to $\mathrm{CD} 4+\mathrm{T}$ cells in the intestine to maintain host tolerance to symbiotic bacteria.

Other non-classical lymphocytes, including $\gamma \delta \mathrm{T}$ cells, natural killer T (NKT) cells, and mucosal-associated invariant $\mathrm{T}$ (MAIT) cells, are also of particular interest in the hostmicrobiome crosstalk, given their abundance in the intestine and liver. A previous study has shown that $\gamma \delta \mathrm{T}$ cells can be directly activated by specific microbial colonization and function as an innate source of IL- $17 .{ }^{44}$ Recently, a unique liverresident $\gamma \delta \mathrm{T}$ cell subset that predominantly produces IL-17 A has been identified, and homeostasis of these liver $\gamma \delta \mathrm{T}$ cells is maintained by the gut microbiome in a lipid antigen/CD1ddependent manner. ${ }^{45}$ Regarding CD1d-dependent invariant NKT (iNKT) cells, early-life contact with commensal microbes is key for tolerance establishment. The iNKT cells in germ-free mice tend to accumulate in colonic lamina propria and exacerbate experimental IBD and asthma, ${ }^{46}$ whereas recognition of sphingolipids derived from Bacteroides fragilis reduces the proliferation of these destructive NKT cells and thus ameliorates the inflammatory disease. ${ }^{47}$ Of note, mouse infection by $N$. aromaticivorans induces anti-mitochondrial antibody (AMA) and T cell-mediated small bile duct damage characteristic of primary biliary cholangitis ( $\mathrm{PBC}$ ), and initiation of this autoimmune attack is dependent on the microbial activation of NKT cells. ${ }^{48}$ Likewise, MAIT cells are restricted by a highly conserved class Ib MHC molecule, the MHC class I-related protein 1 (MR1) ${ }^{49}$ MAIT cells are also important in the hostmicrobiome crosstalk, with the bacterial riboflavin metabolite 5-A-RU being its potent ligand. The absence of MAIT cells in germ-free mice underlies the essence of the commensal microbiome in MAIT cell development. ${ }^{49}$ Intrahepatic MAIT cells have been found to actively respond to bacterialexposed biliary epithelial cells, indicating their potential role in the mucosal homeostasis of bile ducts. ${ }^{50}$

Interaction between the microbiome and adaptive immunity. IgA is the most abundant secretory Ig isotype in the gut and can be produced in both $\mathrm{T}$ cell-independent and in a $\mathrm{T}$ celldependent manner. ${ }^{51}$ Commensal microbial stimulation is required for intestinal IgA responses, with good examples being segmented filamentous bacterium (SFB) and Alcaligenes. ${ }^{52,53}$ However, the intestinal microbiome in low-IgA mice has been shown to degrade the secretory component of secretory IgA and IgA itself, which may account for its 
susceptibility to colitis. ${ }^{54}$ In a reciprocal fashion, IgA has a fundamental role in mucosal defense by coating and entrapping microorganisms and, moreover, immobilizing the microbiome via downregulating the expression of flagella-related genes. ${ }^{55} \mathrm{~A}$ fascinating working hypothesis states that IBD might be preferentially initiated by commensals with high IgA coating, as suggested by the novel techniques in sorting and sequencing immunoreactive pathosymbionts (termed IgA-seq). ${ }^{56}$ An IgAcoated Escherichia coli was found to be specifically enriched in patients with Crohn's disease and concomitant spondyloarthritis, colonization of which was capable of inducing Th17 mucosal immunity. ${ }^{57}$ Coating by IgA enables the translocation of non-invasive microbes, facilitating antigen presentation and subsequent production of antigen-specific IgA. ${ }^{58}$ These IgA, which have undergone somatic hypermutation and affinity maturation, further bind to and select for particular microbes. Therefore, IgA functions to shape and maintain the microbial community. Other immune cells, such as Treg cells and follicular helper $\mathrm{T}$ ( $\mathrm{Tfh}$ ) cells, also impinge on gut microbial diversity through IgA selection in Peyer patches. ${ }^{59,60}$

Germ-free (GF) and antibiotic-treated mice are partially defective in adaptive immunity, characterized by a paucity of intestinal Th17 and Treg cells and a skewing toward Th2. Ivanov et al. ${ }^{61}$ have shown that monocolonization by SFB in mice is sufficient to induce intestinal Th17 cells. Notably, SFBdependent Th17 cells exhibit a dichotomous effect because they confer resistance to enteropathogens in mice, but potentiate autoimmune inflammation in murine models of multiple sclerosis (MS) and rheumatoid arthritis (RA). ${ }^{62,63}$ Moreover, neonatal colonization of SFB in mice and its associated IL-17 signaling has been shown to impact antinuclear antibody production and resultant systemic autoimmunity in adult life. ${ }^{64}$ Subsequent investigations into SFB have suggested that Th17 cell responses to SFB are at least partially antigenspecific. $^{65}$ It has been reported that MHC-II-dependent presentation of SFB antigens by conventional DCs drives mucosal Th17 cell differentiation. ${ }^{66}$ In addition, direct adhesion of SFB to the ileal epithelium induces serum amyloid A proteins 1 and 2 (SAA1/2). In parallel, SFB activates ILC3 to produce IL-22, which further promotes epithelial SAA production. ${ }^{67}$ However, how SAA acts on Th17 cells is unclear. It is hypothesized that CX3CR1+ myeloid cells may respond to SAA and secrete cytokines to promote the polarization of Th17 cells as well as IL-22 production by ILC3. ${ }^{42,68}$ Nonetheless, SFB has not yet been identified in human intestines, whereas Bifidobacterium adolescentis, a human-derived symbiotic bacterial species, acts as an identically potent inducer of Th17 cells via a non-SFB mechanism in murine intestines. ${ }^{69}$ In contrast, depletion of Lactobacillus murinus by high salt consumption may also lead to Th17 dysregulation and autoimmune disorders, which can be rescued by supplementation with $L$. murinus. $^{70}$ The same reduction of Lactobacillus spp. and an increase in Th17 cells due to high salt intake have also been observed in a pilot human study, giving rise to the connection between the diet and the gut-immune axis.
Immunity at mucosal surfaces requires a delicate balance to resist pathogenic infections and maintain tolerance to commensals. Intestinal homeostasis is maintained by Treg cells, which prevent aberrant immune responses toward dietary antigens and the commensal microbiome, thus halting the initiation of immunopathology. Intestinal Treg cells are induced and maintained by certain members of the commensal microbiome, ${ }^{71}$ as supported by the observation that the Bacteroides fragilis-derived polysaccharide, PSA, can restore immunologic deficiency in GF mice. ${ }^{72}$ PSA is a symbiotic factor with a capacity to mediate the conversion of CD4+ $\mathrm{T}$ cells into IL-10-producing Tregs and to ameliorate mucosal inflammation in mice. ${ }^{73,74}$ This immunomodulatory effect requires two IBD-associated genes, ATG16L1 and NOD2, to activate a non-canonical autophagy pathway, which might account for the defective Treg responses in individuals with such risk genes. ${ }^{75}$ Moreover, the anti-inflammatory effect of PSA has been extended to extraintestinal autoimmune mouse models, such as multiple sclerosis. ${ }^{76}$ The work of Atarashi et al. ${ }^{77}$ demonstrates the capability of a selected consortium of Clostridia strains in inducing Treg cells in the murine intestine, in support of the idea that the tolerogenic cell type is largely conferred by local microbial communities. ${ }^{78}$ Mechanistically, this microbial induction of Tregs may be mediated by SCFAs, particularly butyrate, through HDAC inhibition and consequent histone $\mathrm{H} 3$ acetylation of the Foxp3 gene. ${ }^{27}$ Alternatively, SCFAs stimulate the proliferation of Treg cells by activating G-protein-coupled receptors such as GPR43. ${ }^{28}$

Recent studies further add to the complexity of the symbiont-induced Tregs and Th17 cells. Two groups identified a subset of Tregs that generally lack NRP1 and Helios and, surprisingly, express ROR $\gamma \mathrm{t}$, a transcription factor that is thought to antagonize FoxP3 and promote Th17 cell differentiation. ${ }^{79,80}$ This FoxP3+ ROR $\gamma t+$ Treg subtype expresses high levels of IL-10 and CTLA-4 and exhibits enhanced suppressive capacity in experimental colitis. ${ }^{81}$ In parallel, another population of intestinal Treg cells driven by GATA3 is induced by epithelium-derived IL-33. ${ }^{82}$ How the microbiome and other tissue-derived factors regulate the balance between GATA3-expressing and ROR $\gamma$ t-expressing Treg cells remains unknown, but the latter cells are not locally confined. Shifting the Treg balance in the intestine by various environmental factors may have systemic implications leading to the perpetuation of autoimmune injury and chronic inflammation.

Interestingly, it has been suggested that the microbiota might also have an essential role in lymphopenia-associated autoimmunity, which could account for the paradoxical concurrence of autoimmunity and immunodeficiency within an individual. During lymphopenia, peripheral $\mathrm{T}$ cells undergo a process termed 'homeostatic proliferation' to maintain the immune system while giving rise to the possibility of an aberrant expansion of autoreactive clones. ${ }^{83,84}$ Under this circumstance, a two-hit model driven by commensal microbiota has been proposed to explain the pathogenesis of lymphopenia-associated colitis. ${ }^{85}$ First, the microbiota 
stimulates innate cell production of IL-6 via MyD88, which provides signals for the spontaneous proliferation of $\mathrm{T}$ cells. With the presence of microbiota, these $\mathrm{T}$ cells then proliferate in an antigen-specific manner and cause colon inflammation. However, an inconsistently normal or even increased $\mathrm{T}$ cell homeostatic proliferation has been observed in MyD88- and several TLR-deficient mouse models. ${ }^{86}$ Recently, Eri T et al. ${ }^{87}$ have shown that conventional $\mathrm{T}$ cells transferred into athymic mice will proliferate and differentiate into a distinctive PD-1 +CXCR5 - / dim T cell subset, acting as Tfh cells to promote B cell autoantibody production. Depletion of commensal microbiota by antibiotics inhibits differentiation and ameliorates systemic autoimmunity. ${ }^{87}$ Collectively, an indispensable role of the microbiota in lymphopenia-induced autoimmunity has been demonstrated in several models, although the underlying detailed mechanisms are not entirely understood.

\section{The gut microbiome and autoimmune diseases}

Multiple lines of evidence have linked dysbiosis to barrier autoimmunity and beyond, particularly in the setting of IBD, rheumatoid arthritis, type I diabetes and multiple sclerosis (Figure 1). ${ }^{88}$ First, the altered composition and function of the microbiome was assessed in different animal models of autoimmune diseases, mainly using germ-free and gnotobiotic mice colonized with a defined microbe. In parallel, human observational studies have been conducted in patients with autoimmune diseases, using 16s ribosomal RNA (rRNA) sequencing, metagenomic sequencing and metabolomics analysis. As a result, human studies have led to large amounts of descriptive data for which mechanistic interpretations should be obtained from experimental models; however, therapeutic attempts are already ongoing in clinical settings.

Rheumatoid arthritis (RA). Environmental factors are likely to have a pivotal role in the development of RA in genetically prone individuals, ${ }^{89}$ and the microbiome is a presumed culprit because germ-free mice are protected against experimental arthritis. $^{63,90}$ The introduction of SFB in GF $\mathrm{K} / \mathrm{BxN}$ mice restores the production of autoantibodies and arthritis by inducing Th17 cells in the intestinal lamina propria. ${ }^{63}$ One possible mechanism for this phenomenon is that the commensal microbiome induces DC and macrophage production of pro-inflammatory cytokines such as IL- $1 \beta$ and IL-6, which facilitate Th17 differentiation and the onset of arthritis. ${ }^{91}$ IL-10-producing Breg cells are induced in mice by the same signals, IL- $1 \beta$ and IL- 6 , triggered by the microbiome, ${ }^{92}$ thus

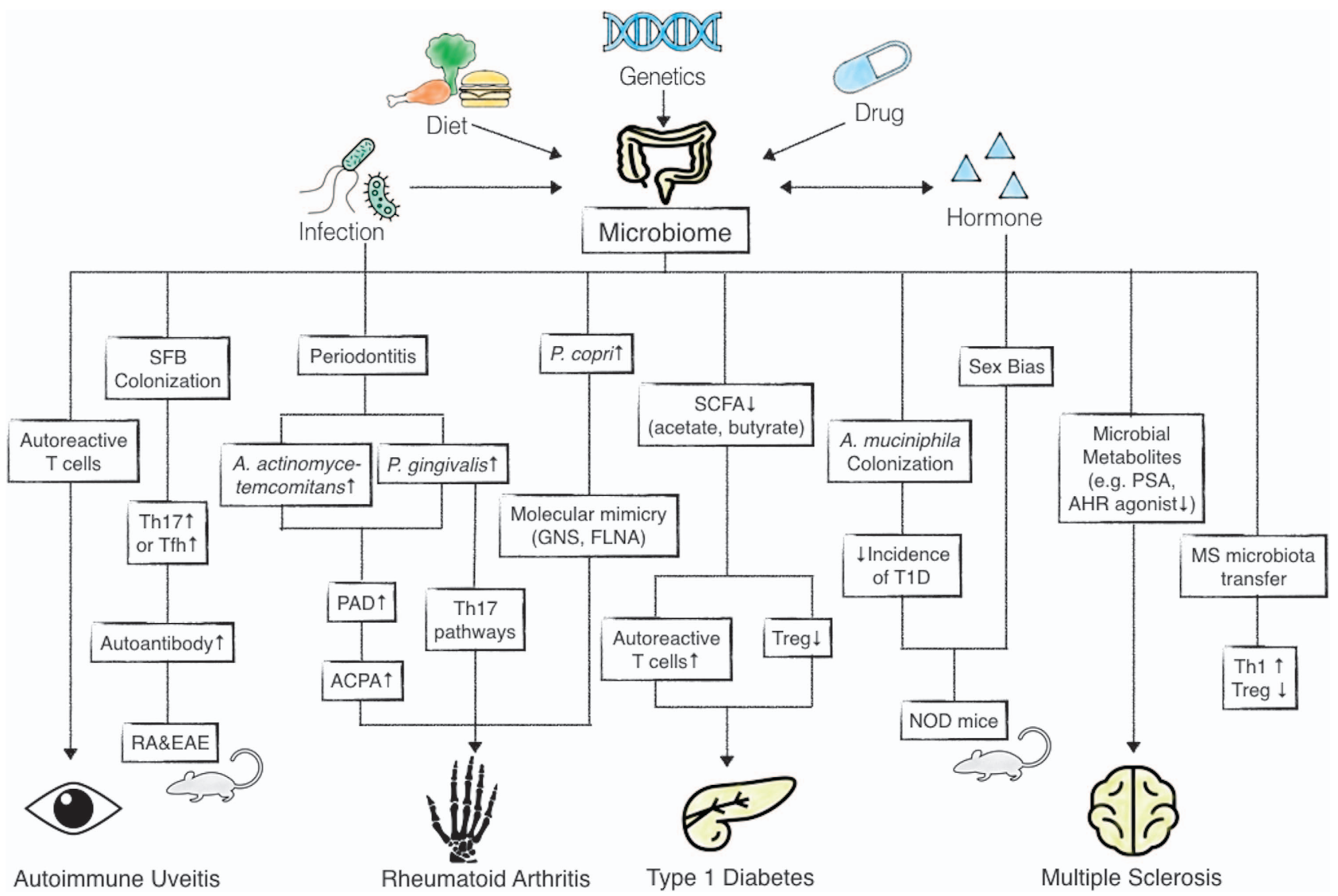

Figure 1 The proposed link between the gut microbiome and systemic autoimmune diseases such as rheumatoid arthritis (RA), type 1 diabetes (T1D) and multiple sclerosis (MS). PAD, peptidylarginine deiminase; ACPA, anti-citrullinated protein antibodies; GNS, $N$ acetylglucosamine-6-sulfatase; FLNA, filamin A; SCFAs, short-chain fatty acids; NOD, non-obese diabetes; PSA, polysaccharide derived from Bacteroides fragilis; AHR, aryl hydrocarbon receptor; SFB, segmented filamentous bacterium; Tfh, follicular helper T cell; EAE, experimental autoimmune encephalomyelitis. 
supporting a dual role of the microbiome in establishing both pro-inflammatory and regulatory immune responses. Intriguingly, $\mathrm{Wu}$ and colleagues ${ }^{93}$ recently proposed a previously unknown conception that gut commensals, exemplified by SFB, might selectively expand Th17 cells expressing dual TCRs, which recognize both SFB antigens and self-antigens. These Th17 cells are recruited though the CCL20-CCR6 axis to the lung, where they trigger RA-related lung pathology. This dual TCR mechanism, independent of molecular mimicry or bystander activation, has yielded new sights into how the commensal microbiota modulate host autoimmunity.

Patients with new-onset RA manifest a microbiota enriched for the pathobiont Prevotella copri, whereas patients with established RA have significantly lower abundance, possibly due to the impact of treatment ${ }^{94}$ and the presence of IgG or IgA antibodies that are reactive to $P$. copri in RA subgroups. ${ }^{95}$ Two autoantigens, $N$-acetylglucosamine-6-sulfatase (GNS) and filamin A (FLNA), have shown marked sequence homology to epitopes of gut microbes, such as Prevotella sp., further supporting the molecular mimicry theory in RA. ${ }^{96}$ Recently, a metagenome-wide association study comparing RA patients and healthy controls has confirmed a perturbed microbiome in the intestine, dental region and saliva, which was partially resolved after RA treatment. ${ }^{97}$ A discrete concordance exists between the gut and oral microbiomes in individuals with RA, suggesting an overlap in their pathogenicity at different body sites, particularly considering the proposed link between periodontal infection by Porphyromonas gingivalis and RA. Periodontitis is more prevalent in RA and is associated, in particular, with high levels of anti-citrullinated protein antibodies (ACPA). ${ }^{98}$ Mechanistic studies in mouse models have revealed an involvement of Th17-related pathways in this autoimmune arthritis model driven by periodontal pathogens. ${ }^{99}$ There is increasing evidence that the link between these two diseases is due to the unique peptidylarginine deiminase (PAD) enzyme expressed by $P$. gingivalis, which specifically citrullinates peptides from key autoantigens of RA and thus breaks immune tolerance. ${ }^{100}$ An alternative pathogenic candidate may be Aggregatibacter actinomycetemcomitans, which triggers hypercitrullination in host neutrophils. ${ }^{101}$

Type I diabetes (T1D). A significant contribution of nongenetic factors has been recognized in the development of T1D since a marked discrepancy exists between individuals carrying T1D-associated HLA risk alleles and those who develop the disease. $^{102}$ A multi-hit model for T1D has recently been suggested by a prospective study of 33 infants who were genetically predisposed to $\mathrm{T} 1 \mathrm{D}$, showing that changes in the gut microbiome occur after seroconversion to autoantibody positivity but before the onset of T1D. ${ }^{103}$ The notion that the gut microbiome may be involved in T1D pathogenesis through the connection between the gut and the pancreas has also been well established in murine models. ${ }^{13,104-106}$ For example, nonobese diabetic (NOD) mice lacking MyD88, a downstream adaptor for multiple TLR-related signaling pathways, are protected against diabetes, but this effect was abrogated in the absence of commensal bacteria. ${ }^{13}$ Transfer of the gut microbiome from these diabetes-protected MyD88-deficient NOD mice shaped mucosal immunity and further delayed the onset of diabetes in the recipients. ${ }^{107}$ The possible involvement of molecular mimicry by the microbiome in immune tolerance breakdown in $\mathrm{T}_{10} \mathrm{D}^{108}$ is supported by the development of accelerated T1D in MyD88-/- mice due to an altered intestinal microbiome encompassing a microbial peptide mimic of IGRP, an islet-specific autoantigen. ${ }^{108}$ Conversely, expression of certain MHC-II alleles can protect NOD mice from autoimmune insulitis, which seems to be mediated by the intestinal microbiota. ${ }^{109}$ More importantly, this protection occurs during a critical early window of ontogeny, highlighting the possibility of modulating the microbiota at an early stage to prevent autoimmune diseases. In addition, gut microbial metabolites also appear to be protective, and feeding NOD mice a combined acetate- and butyrate-yielding diet prevents the development of T1D, mainly through autoreactive $\mathrm{T}$ cells limited by acetate and Treg cells boosted by butyrate. ${ }^{110}$ Very recently, it was demonstrated that the transfer of a single symbiont, Akkermansia muciniphila, to NOD mice, instead of the whole microbial community, could significantly lower the incidence of T1D, with its multiple immunologic and metabolic signaling remodeling effects. ${ }^{111}$ In agreement with these experimental data, a series of cohort studies have shown a specifically altered microbiome profile in individuals with preclinical T1D, including a sharp decrease in microbiome diversity, low community stability, a dominating abundance of the Bacteroides genus, fewer Bifidobacterium species, and a dearth of butyrate-producing and lactate-producing species. ${ }^{103,112,113}$

Although sexual dimorphism is another prominent feature of many autoimmune diseases that predominantly affect women, T1D is one of the few exceptions. NOD mice are characterized by spontaneous, immune-mediated loss of pancreatic $\beta$ cells mimicking T1D, while displaying a strong gender bias. Strikingly, germ-free conditions reverse the differences of T1D incidence commonly observed between male and female NOD mice and transfer of the male microbiome to female mice is protective against T1D, possibly via protective testosterone levels. ${ }^{114}$ However, another group has reported that hormones contribute reciprocally to the sex-based microbial differences. ${ }^{114}$ The higher testosterone level in adult NOD male mice selectively enriches organisms such as SFB and an E. colilike species, which in turn upregulate host testosterone. Collectively, these two factors, that is, the microbiome and hormones, might work as a feedback loop to influence the incidence of autoimmune diseases other than T1D. ${ }^{115}$

Multiple sclerosis (MS). The initiation of autoimmunity in individuals who are genetically predisposed to MS has been attributed to environmental factors, particularly microbial infection, based on data from murine models of experimental autoimmune encephalomyelitis (EAE). ${ }^{116}$ Earlier evidence from a spontaneous, relapsing-remitting mouse model of EAE has shown that the commensal microbiome is required 


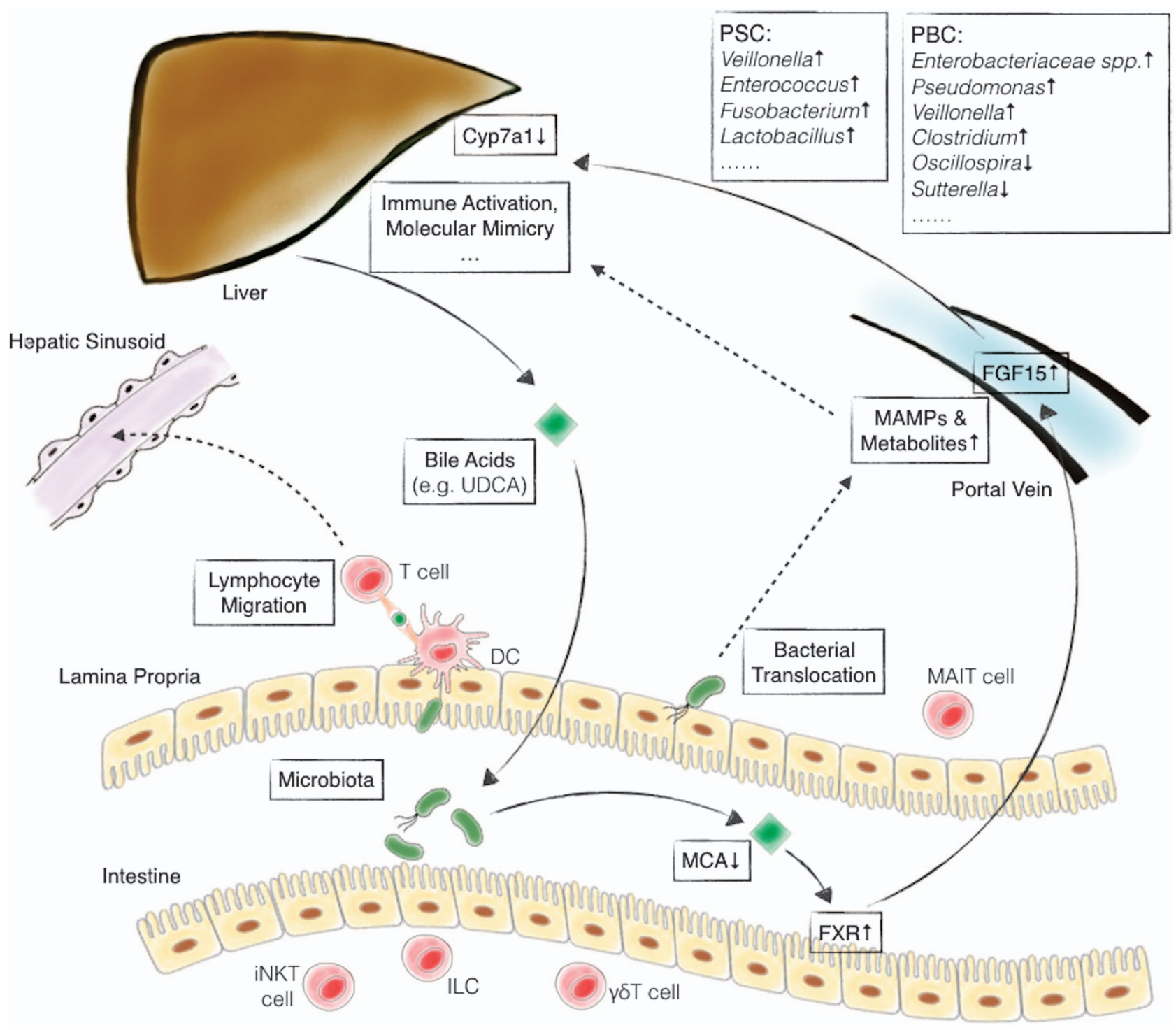

Figure 2 The paradigm of gut microbiome involvement in liver autoimmunity. On the basis of the gut-liver axis, bacterial translocation, migration of gut-primed lymphocytes to the liver, bile acids and nuclear receptor signaling are involved in PBC and PSC pathogenesis. Cyp7a1, cholesterol 7 alpha-hydroxylase; Fgf15, fibroblast growth factor 15; MAMPs, microbe-associated molecular patterns; UDCA, ursodeoxycholic acid; MCA, muricholic acid; FXR, farnesoid X receptor; PSC, primary sclerosing cholangitis; PBC, primary biliary cholangitits; iNKT cell, invariant natural killer T cell; ILC, innate lymphoid cell; $\gamma \delta T$ cell; MAIT cell, mucosal-associated invariant T cell.

to induce self-reactive $B$ cells upon simulation with the autoantigen, myelin oligodendrocyte glycoprotein (MOG). ${ }^{117}$ Germ-free mice exhibit compromised EAE; however, colonization of SFB alone restores the disease severity comparable to conventionally raised mice. ${ }^{62}$ Conversely, administration of PSA derived from $B$. fragilis protects mice against central nervous system (CNS) demyelination and inflammation by tissue-specific expansion of CD4+Foxp3+Tregs expressing CD39. ${ }^{76,118}$ Intriguingly, it has recently been shown that the metabolism of dietary tryptophan into AHR agonists by the gut microbiome also seems to be involved in the gut-brain axis. $^{31,119}$ These intestinal metabolites enter the systemic circulation and act on astrocytes to alleviate CNS inflammation. ${ }^{119}$ Consistently, decreased levels of circulating AHR agonists are observed in individuals with MS, and cross-sectional human studies of relatively small cohorts suggest a distinct alteration in the MS gut microbiome compared with healthy controls. ${ }^{120,121}$ A study of 60 relapsing-emitting MS cases has reported an increased abundance of Methanobrevibacter (Archaea) and Akkermansia and a reduction in Butyricimonas. ${ }^{120}$ Notably, two recent studies, by combining cohort analysis and in vitro and in vivo experiments, further propelled the mechanistic study. ${ }^{122,123}$ Although no overt difference in the overall microbial profile was found in 34 monozygotic twin pairs who were discordant for MS, when transplanted into the spontaneous mouse model of EAE, the gut microbiota derived from twin bearing MS aggravated the disease compared with the healthy twin-derived microbiota. ${ }^{122}$ In a study by Cekanaviciute et al., ${ }^{123}$ the microbiomes of 71 untreated MS patients were analyzed. By subsequently exposing 
PBMCs to bacterial extracts and monocolonizing mice with specific species, they showed that MS-associated bacteria indeed shifted $\mathrm{T}$ cells toward a pro-inflammatory profile. For instance, Akkermansia muciniphila, which was increased in MS patients, boosted Th1 cell differentiation. In tandem with the study by Berer et al., ${ }^{122}$ the compromised IL-10 production by Treg cells in mice colonized with MS patient-derived microbiota was also addressed. ${ }^{123}$ These two independent studies, by defining the potential mechanisms of $\mathrm{T}$ cell autoimmunity induced by commensal microbiota, have improved our understanding of the causal link between the microbiome and autoimmune disease.

\section{Gut microbiome and liver autoimmunity}

With $70 \%$ of its blood supply derived from the portal vein, the liver is physiologically exposed to gut-derived microbial components and metabolites, and intestinal dysbiosis has been associated not only with liver diseases, including non-alcoholic fatty liver disease (NAFLD), but also inflammatory, fibrotic or cholestatic conditions. ${ }^{124}$ Not surprisingly, this gut-liver axis has also been implicated in autoimmune liver disease (Figure 2), as well represented by primary sclerosing cholangitis (PSC) and primary biliary cholangitis (PBC). ${ }^{125,126}$

Bacterial translocation and immune activation in the liver. As mentioned above, the intestinal mucosal immune system, particularly mesenteric lymph nodes (MLNs), compartmentalizes the commensal microbiome. In addition to MLNs, the liver acts as a second firewall to eradicate bacteria that have overcome intestinal barriers. ${ }^{127}$ Notably, this function seems to be compromised in chronic liver diseases, but how Kupffer cells fail to clear intestinal microbes during the course of liver disease remains unclear. In this regard, the liver is not only a recipient but a filter of gut-derived agents with Kupffer cells, hepatic sinusoidal endothelial cells (HSECs) and biliary epithelial cells (BECs) all expressing PRRs, and they are able to sense microbe-associated molecular patterns (MAMPs) such as bacterial LPS, peptidoglycans, flagellin and bacterial DNA, among other ligands. The excessive immune responses elicited by these MAMPs are thought to lead to liver injury and fibrosis, and consistent with this hypothesis, a recent study has described a gut-vascular barrier (GVB) that controls microbiome translocation, which is impaired in celiac disease patients with unexplained elevated serum transaminases. ${ }^{128}$ As a result of these changes, bacterial translocation might drive extraintestinal inflammation, with hepatocytes and cholangiocytes being the vulnerable cell types.

The 'leaky gut' hypothesis has been exemplified in NAFLD as well as in PBC and PSC. For instance, a deficient NLRP6 and NLRP3 inflammasome aggravates liver steatosis as a consequence of TLR4 and TLR9 agonists in the portal circulation. ${ }^{129}$ Knockout of CX3CR1 in mice increases endotoxin in portal serum and promotes steatohepatitis. ${ }^{130}$ Bacterial lipoteichoic acid is detected around the damaged bile ducts in PBC, and chronic bacterial exposure in normal mice leads to autoantigen production and subsequent cholangitis that mimics PBC. ${ }^{131}$
In addition, perinuclear antineutrophil cytoplasmic antibodies (p-ANCAs) detected in PSC may target beta-tubulin isotype 5 (TBB-5) as an autoantigen as well as an evolutionary bacterial protein, FtsZ, ${ }^{132}$ giving rise to the hypothesis of an immune cross-reactivity to gut microorganisms. In humans, it is likely that genetic polymorphisms that impair immune responses to the gut microbiome are partially responsible for liver diseases. Indeed, GWASs have established several genetic susceptibility loci shared by PSC and IBD, including CARD-9, fucosyltransferase 2 (FUT-2) and macrophage-stimulating protein 1 (MST-1), among others. ${ }^{133-136}$ Proteins encoded by these genes are intimately involved in innate and adaptive immunity, as illustrated by the fucosylation of intestinal epithelial cells by FUT-2, which also maintains host-microbiome symbiosis. Patients with PSC carrying FUT-2 variants have a different microbial pattern in the bile and colon and, more importantly, are associated with an increased frequency of biliary infections and incidence of dominant stenosis. ${ }^{137}$ CARD-9, an important downstream mediator of NOD2 and TLR signaling, has recently been related to IL-22 production and gut integrity. Mice deficient in CARD-9 display increased susceptibility to colitis due to a loss of bacterial species capable of metabolizing tryptophan into AHR agonists. ${ }^{33}$

Migration of mucosal lymphocyte to the liver. In parallel to the 'leaky gut' hypothesis, a 'gut lymphocyte homing' hypothesis has been proposed to explain this gut-liver axis associated with PSC and PBC. Mucosal lymphocytes are characterized by the expression of integrin $\alpha 4 \beta 7$ and chemokine receptor CCR9, which bind to the endothelial adhesion molecule MAdCAM-1 and chemokine CCL25, respectively. However, aberrant expression of MAdCAM-1 and CCL25 has been detected in hepatic sinusoidal endothelium in inflammatory liver disease, including PSC, ${ }^{138}$ leading to the hypothesis that the gut-primed $\mathrm{T}$ cells are abnormally recruited to the liver and may trigger autoimmune reactions upon recognition of the corresponding antigens. ${ }^{139}$ Indeed, in a mouse model of ovalbumin-induced colitis, $\mathrm{T}$ cells primed in the GALT by ovalbumin migrate to the liver and cause cholangitis when recognizing the same antigen, ovalbumin, on cholangiocytes. ${ }^{140}$ Considering the strong association between PSC and IBD and the defined role of the microbiome in IBD pathogenesis, it is tempting to assume that mucosal $\mathrm{T}$ cells are aberrantly activated by the commensal microbiome, further migrate to the liver and crossreact with antigens present in the liver. In line with this hypothesis, a recent sequencing study of the TCR $\beta$ chain has demonstrated that the gut-infiltrating and liver-infiltrating $\mathrm{T}$ cells in PSC-IBD patients are clonally related and may be able to recognize the same antigens. ${ }^{141}$ In addition to $\mathrm{T}$ cells, intrahepatic IgA-producing $\mathrm{B}$ cells are derived from gutassociated lymphoid tissues and are directed against commensal antigens. ${ }^{142}$ Given the increased serum levels of IgA often observed in chronic liver diseases, in particular PBC and PSC, this finding further highlights the potential involvement of the gut-liver axis in these immune disorders. 
However, the mechanisms by which liver endothelial cells express gut-specific molecules remain elusive, although it has been speculated that the upregulation of hepatic vascular adhesion protein (VAP)-1 in PSC is responsible for the aberrant expression of liver MAdCAM-1. ${ }^{125}$ Cysteamine and other amines derived from gut bacteria and diets can enter the liver via the portal vein and act as substrates for VAP-1, a potent amine oxidase, leading to the generation of catabolites that induce MAdCAM-1 expression on HSECs. ${ }^{143}$

The gut microbiome, bile acids and nuclear receptor signaling. Apart from direct interaction with the immune system, relationships between the microbiome and bile acids (BA) are also representatives of the gut-liver crosstalk. ${ }^{144}$ Bile acids are primarily produced in hepatocytes and then metabolized into secondary bile acids by bacteria in the gut lumen. Early works have reported that the BA composition of GF mice is distinct from their conventionally raised (CONV-R) counterparts. Sayin et al. ${ }^{145}$ have provided insights into the field by showing that CONV-R mice exhibit a decreased proportion of tauro-beta-muricholic acid (T $\beta \mathrm{MCA}$ ) as well as a significantly reduced size of the BA pool. More importantly, MCAs are potent farnesoid X receptor (FXR) antagonists, and the gut microbiome can regulate BA synthesis in the liver by alleviating FXR inhibition in the ileum. Specifically, FXR activation in the intestine induces fibroblast growth factor 15 (FGF15) expression, which then reaches the liver and blocks $7-\alpha$-hydroxylase (CYP7A1), the rate-limiting enzyme in BA synthesis. Microbiome remodeling by antibiotics or antioxidants increases
T $\beta$ MCA and suppresses intestinal FXR signaling. ${ }^{146,147}$ Conversely, BA extensively modulates the microbiome directly or indirectly through activation of the innate immune system and further influences host physiology via the FXR and G-proteincoupled bile acid receptor TGR5. ${ }^{148}$ Indeed, the dynamics of host bile acids results in an altered composition of the gut microbiome in rats. ${ }^{149}$ Application of the FXR agonist obeticholic acid to cirrhotic rats partially prevents gut barrier dysfunctions and attenuates intestinal inflammation, leading to reduced bacterial translocation. ${ }^{150}$ Using GF and Fxr-/mice, a recent study has demonstrated that diet-induced obesity and liver steatosis promoted by microbiome is dependent on its regulation of the BA profile and FXR signaling. ${ }^{151}$ Moreover, this altered FXR signaling can further shift the gut microbiome toward a more obesogenic configuration, and the circuitry of the gut microbiome, bile acids, and nuclear receptor signaling operates to impact host metabolism as well as hepatic pathogenesis.

The gut microbiome and autoimmune liver disease. Several sequencing studies have reported an altered gut microbial community in PSC and PBC, although there are discrepancies, in particular at the genus and species levels.

Our group has recently conducted $16 \mathrm{~s}$ ribosomal RNA (rRNA) sequencing of the fecal microbiome of a PBC cohort, prior to UDCA use to avoid the confounding effect of bile acids. Moreover, a prospective study of $37 \mathrm{PBC}$ patients before and after 6 months of UDCA treatment has also been performed. ${ }^{152}$ The gut microbiome in UDCA-naïve $\mathrm{PBC}$

Table 1 Comparison of published studies of gut microbiome in PSC

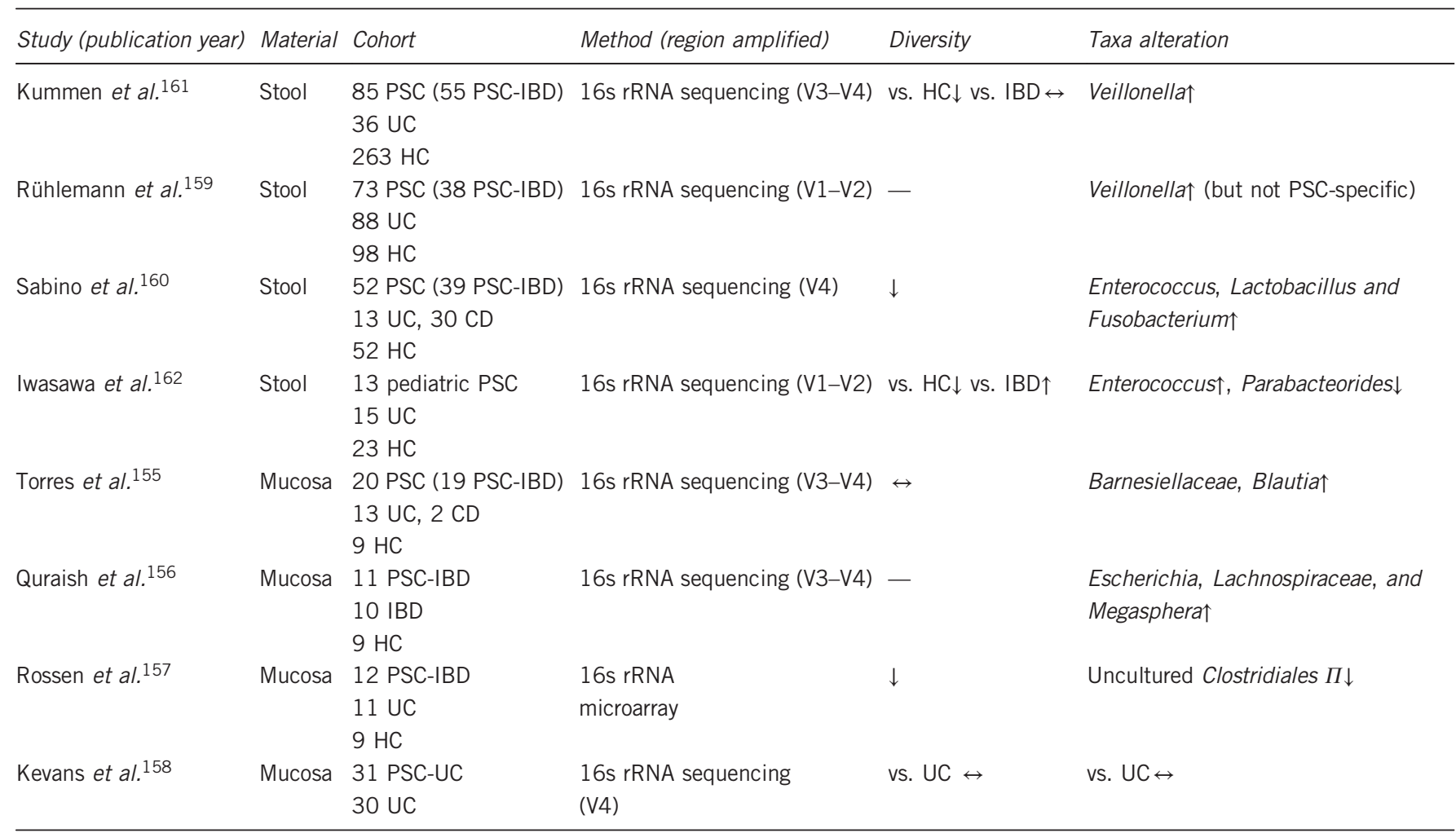


exhibits a significantly reduced within-individual microbial diversity compared with healthy controls. This finding is inconsistent with a previous study using a relatively small PBC cohort, likely due to the influence of UDCA treatment. ${ }^{153}$ A microbial signature of $\mathrm{PBC}$ defined by 12 genera can be used to accurately distinguish $\mathrm{PBC}$ from controls in the validation cohort (with an AUC of 0.84-0.86). An increased unknown genus in the family of Enterobacteriaceae shows the strongest association with PBC, followed by Pseudomonas, Veillonella and Clostridium, whereas Oscillospira and Sutterella were decreased in the PBC cohort. Notably, among these 12 PBC-associated genera, the abundance of 6 was reversed after 6 months of UDCA treatment, ${ }^{152}$ in parallel with the treatment response, thus suggesting that the gut microbiome may be a potential target for the treatment of PBC.

Given the coexistance of IBD in up to $60-80 \%$ of PSC cases, the gut-liver axis has been linked to the pathogenesis of PSC. Published studies with sample sizes ranging from 11 to 85 patients have confirmed a distinct microbial profile in PSC. ${ }^{154}$ In general, the gut microbiome in PSC shows a marked deviation from healthy controls, characterized by a reduced microbial diversity (Table 1). Changes in the abundances of specific bacteria, such as Enterococcus and Veillonella, have been observed in different studies, and some might be used as biomarkers of PSC. Four of these studies analyzed mucosal biopsies, ${ }^{155-158}$ whereas others have focused on the fecal microbiome. ${ }^{159-162}$ The study by Kummen et al. ${ }^{161}$ is the largest assessment of the fecal gut microbiome in PSC, resulting in the identification of a less diverse microbial profile in PSC, with Veillonella being a PSC-associated genus. However, the difference in the Veillonella genus in PSC was no longer significant when patients with liver cirrhosis were excluded, according to the study by Sabino et al. ${ }^{160}$ In addition, Sabino et al. ${ }^{160}$ identified three enriched genera in PSC, namely, Enterococcus, Fusobacterium and Lactobacillus, regardless of concomitant IBD or UDCA treatment. Among confounding factors, salazosulfapyridine (SASP) treatment should be excluded when analyzing the gut microbiome of patients with PSC, whereas data from mucosal microbiome are more heterogeneous than fecal ones, possibly due to the smaller sample size. ${ }^{154}$ Housing different PSC mouse models in germfree facilities leads to contradictory conclusions because NOD. c3c4 mice develop cholangitis spontaneously with a specific gut microbiome, but they manifest a milder phenotype under GF conditions. ${ }^{163}$ In contrast, mdr2(-/-) mice under GF conditions exhibit exacerbated PSC-like manifestations with more severe cholestasis, liver fibrosis, a ductular reaction and ductopenia, without secondary bile acids. ${ }^{164}$ The administration of UDCA, a commensal bacterial metabolite, abrogates cholangiocyte senescence in vitro, ${ }^{164}$ and these discrepancies might be attributed to the distinct host genotype and pathogenic mechanisms in these two models.

\section{Perspectives and future directions}

The commensal microbiome utilizes multiple pathways to shape mucosal immunity, and its impact may reach non-mucosal tissues and thus contribute to systemic autoimmunity in genetically susceptible individuals. The currently available techniques to detail the functions of the intestinal microbiome has provided more accurate information regarding the microbial changes in human autoimmune diseases. However, the scenario is complicated by the variability of the intestinal flora over short periods of time, which does not allow a historical perspective of the observed changes years after the initiation of the autoimmune process. Whether the observed changes are the cause or the consequence of the disease (or its treatment) remains enigmatic. Under this circumstance, several hypotheses have been proposed, aiming at explaining the causal link between the commensal microbiota and the development of diseases. Molecular mimicry, in which the gut microbiota may serve as a source of cross-reactive antigens that trigger autoimmune reactions, was postulated many years ago and is still being re-assessed and validated in different models ${ }^{9,10,96}$ Nevertheless, overwhelming data suggest a multifaceted effect of the microbiota on host physiology. ${ }^{165}$ In most cases, a perturbed microbiota may exacerbate the immune disorder in the setting of genetic susceptibility rather than ignite an initial autoimmune attack.

Undoubtedly, larger, longitudinal and well-controlled microbiome-wide studies are expected in the future field of autoimmune diseases, to better understand the potential confounders as well as the importance of the observed differences. For example, the use of samples from monozygotic twin pairs who were discordant for a disease has, to a large extent, excluded differences derived from genetics, location and diet. ${ }^{122}$ In addition, it seems necessary to consider the influence of drug therapy when analyzing the microbiota. ${ }^{94,152}$ It should be noted that the study of the microbiome has begun to shift from merely describing the association between commensal communities and diseases to exploring the detailed immunologic and metabolic function of specific microbes and, further, seeking for adjuvant therapeutics based on fecal microbiota transplantation (FMT) or application of microbiota-derived bioactive molecules such as probiotics and prebiotics, ${ }^{166,167}$ which hold great promise for future clinical improvements of autoimmune disorders as well as inflammatory diseases.

Although mouse models have now been extensively used to interpret the contribution of colonization by a single microbe, it should be taken into consideration that the human and murine intestinal microbiota have substantial differences. ${ }^{168}$ Moreover, conclusions should be made with caution because the rearing facilities and genetic backgrounds of animal models have been shown to impact their microbial composition and the disease phenotype, ${ }^{163,164}$ potentially leading to poor repeatability in microbiome-associated experiments. Another issue is the age window of dysbiosis-induced autoimmunity, which has been emphasized in several diseases. ${ }^{109,169}$ Consistently, a largecohort, prospective study has demonstrated that probiotic supplementation as early as 0-27 days is correlated with a reduced risk of islet autoimmunity, ${ }^{170}$ highlighting the effective of the timing of microbiota-associated interventions. Finally, the majority of the current data are gathered from the intestinal 
microbiota, but other skin and mucosal sites, as well as viruses and fungi, have important roles in the microbiota, underscoring the level of complexity that will need to be solved in the future. ${ }^{171,172}$

\section{CONFLICT OF INTEREST}

The authors declare no conflict of interest.

\section{ACKNOWLEDGEMENTS}

This work was supported by awards from the National Nature Science Foundation of China (\#81771732 and 81620108002 to Xiong Ma, \#81400608 to Ruqi Tang).

1 Pillai S. Rethinking mechanisms of autoimmune pathogenesis. J Autoimmun 2013; 45: 97-103.

2 Generali E, Ceribelli A, Stazi MA, Selmi C. Lessons learned from twins in autoimmune and chronic inflammatory diseases. J Autoimmun 2017; 83: 51-61.

3 Xie H, Guo R, Zhong H, Feng Q, Lan Z, Qin B et al. Shotgun metagenomics of 250 adult twins reveals genetic and environmental impacts on the gut microbiome. Cell Syst 2016; 3: 572-584 e573.

4 Zhou S, Xu R, He F, Zhou J, Wang Y, Zhou J et al. Diversity of gut microbiota metabolic pathways in 10 pairs of chinese infant twins. PLoS One 2016; 11: e0161627.

5 Round JL, O'Connell RM, Mazmanian SK. Coordination of tolerogenic immune responses by the commensal microbiota. J Autoimmun 2010; 34: J220-J225.

6 Ruff WE, Kriegel MA. Autoimmune host-microbiota interactions at barrier sites and beyond. Trends Mol Med 2015; 21: 233-244.

7 Floreani A, Leung PS, Gershwin ME. Environmental basis of autoimmunity. Clin Rev Allergy Immunol 2016; 50: 287-300.

8 Nielsen PR, Kragstrup TW, Deleuran BW, Benros ME. Infections as risk factor for autoimmune diseases-a nationwide study. J Autoimmun 2016; 74: 176-181.

9 Campisi L, Barbet G, Ding Y, Esplugues E, Flavell RA, Blander JM. Apoptosis in response to microbial infection induces autoreactive TH17 cells. Nat Immunol 2016; 17: 1084-1092.

10 Horai R, Zarate-Blades CR, Dillenburg-Pilla P, Chen J, Kielczewski $\mathrm{JL}$, Silver PB et al. Microbiota-dependent activation of an autoreactive $\mathrm{T}$ cell receptor provokes autoimmunity in an immunologically privileged site. Immunity 2015; 43: 343-353.

11 Vatanen $T$, Kostic AD, d'Hennezel E, Siljander H, Franzosa EA, Yassour $\mathrm{M}$ et al. Variation in microbiome LPS immunogenicity contributes to autoimmunity in humans. Cell 2016; 165: 842-853.

12 Isailovic N, Daigo K, Mantovani A, Selmi C. Interleukin-17 and innate immunity in infections and chronic inflammation. J Autoimmun 2015; 60: 1-11.

13 Wen L, Ley RE, Volchkov PY, Stranges PB, Avanesyan L, Stonebraker $A C$ et al. Innate immunity and intestinal microbiota in the development of type 1 diabetes. Nature 2008; 455: 1109-1113.

14 Vijay-Kumar M, Aitken JD, Carvalho FA, Cullender TC, Mwangi S, Srinivasan $\mathrm{S}$ et al. Metabolic syndrome and altered gut microbiota in mice lacking toll-like receptor 5. Science 2010; 328: 228-231.

15 Couturier-Maillard A, Secher T, Rehman A, Normand S, De Arcangelis A, Haesler R et al. NOD2-mediated dysbiosis predisposes mice to transmissible colitis and colorectal cancer. J Clin Invest 2013; 123: 700-711.

16 Li YY, Pearson JA, Chao C, Peng J, Zhang X, Zhou Z et al. Nucleotidebinding oligomerization domain-containing protein 2 (Nod2) modulates T1DM susceptibility by gut microbiota. J Autoimmun 2017; 82: 85-95.

17 Ramanan D, Tang MS, Bowcutt R, Loke P, Cadwell K. Bacterial sensor Nod2 prevents inflammation of the small intestine by restricting the expansion of the commensal Bacteroides vulgatus. Immunity 2014: 41: 311-324.

18 Levy M, Thaiss CA, Zeevi D, Dohnalova L, Zilberman-Schapira G, Mahdi JA et al. Microbiota-modulated metabolites shape the intestinal microenvironment by regulating NLRP6 inflammasome signaling. Cell 2015; 163: 1428-1443.

19 Chudnovskiy A, Mortha A, Kana V, Kennard A, Ramirez JD, Rahman A et al. Host-protozoan interactions protect from mucosal infections through activation of the inflammasome. Cell 2016; 167: e414.

20 Skopelja-Gardner S, Jones JD. Rigby WFC. "NETtling" the host: breaking of tolerance in chronic inflammation and chronic infection. J Autoimmun 2017; 88: 1-10.

21 Demoruelle MK, Bowers E, Lahey LJ, Sokolove J, Purmalek M, Seto NL et al. Antibody responses to citrullinated and noncitrullinated antigens in the sputum of subjects with and at-risk for rheumatoid arthritis. Arthritis Rheumatol 2017; doi:10.1002/ art.40401.

22 Lee KH, Kronbichler A, Park DD, Park Y, Moon H, Kim $\mathrm{H}$ et al. Neutrophil extracellular traps (NETs) in autoimmune diseases: a comprehensive review. Autoimmun Rev 2017; 16: 1160-1173.

23 Vong L, Lorentz RJ, Assa A, Glogauer M, Sherman PM. Probiotic Lactobacillus rhamnosus inhibits the formation of neutrophil extracellular traps. J Immunol 2014; 192: 1870-1877.

24 Vong L, Pinnell LJ, Maattanen P, Yeung CW, Lurz E, Sherman PM. Selective enrichment of commensal gut bacteria protects against Citrobacter rodentium-induced colitis. Am J Physiol Gastrointest Liver Physiol 2015; 309: G181-G192.

25 Vong L, Yeung CW, Pinnell LJ, Sherman PM. Adherent-invasive Escherichia coli exacerbates antibiotic-associated intestinal dysbiosis and neutrophil extracellular trap activation. Inflamm Bowel Dis 2016; 22: 42-54.

26 Schroeder BO, Backhed F. Signals from the gut microbiota to distant organs in physiology and disease. Nat Med 2016; 22: 1079-1089.

27 Furusawa Y, Obata Y, Fukuda S, Endo TA, Nakato G, Takahashi D et al. Commensal microbe-derived butyrate induces the differentiation of colonic regulatory T cells. Nature 2013; 504: 446-450.

28 Smith PM, Howitt MR, Panikov N, Michaud M, Gallini CA, Bohlooly YM et al. The microbial metabolites, short-chain fatty acids, regulate colonic Treg cell homeostasis. Science 2013; 341: 569-573.

29 Macia L, Tan J, Vieira AT, Leach K, Stanley D, Luong S et al. Metabolite-sensing receptors GPR43 and GPR109A facilitate dietary fibre-induced gut homeostasis through regulation of the inflammasome. Nat Commun 2015; 6: 6734.

30 Desai MS, Seekatz AM, Koropatkin NM, Kamada N, Hickey CA, Wolter $\mathrm{M}$ et al. A dietary fiber-deprived gut microbiota degrades the colonic mucus barrier and enhances pathogen susceptibility. 2016Cell 167: 1339-1353.

31 Zelante T, lannitti RG, Cunha C, De Luca A, Giovannini G, Pieraccini G et al. Tryptophan catabolites from microbiota engage aryl hydrocarbon receptor and balance mucosal reactivity via interleukin-22. Immunity 2013; 39: 372-385.

32 Schiering C, Wincent E, Metidji A, Iseppon A, Li Y, Potocnik AJ et al. Feedback control of AHR signalling regulates intestinal immunity. Nature 2017; 542: 242-245.

33 Lamas B, Richard ML, Leducq V, Pham HP, Michel ML, Da Costa G et al. CARD9 impacts colitis by altering gut microbiota metabolism of tryptophan into aryl hydrocarbon receptor ligands. Nat Med 2016; 22: 598-605.

34 He B, Hoang TK, Wang T, Ferris M, Taylor CM, Tian X et al. Resetting microbiota by Lactobacillus reuteri inhibits $T$ reg deficiency-induced autoimmunity via adenosine A2A receptors. J Exp Med 2017; 214: 107-123.

35 Fung TC, Bessman NJ, Hepworth MR, Kumar N, Shibata N, Kobuley D et al. Lymphoid-tissue-resident commensal bacteria promote members of the IL-10 cytokine family to establish mutualism. Immunity 2016; 44: 634-646.

36 Sonnenberg GF, Monticelli LA, Alenghat T, Fung TC, Hutnick NA, Kunisawa J et al. Innate lymphoid cells promote anatomical containment of lymphoid-resident commensal bacteria. Science 2012; 336: 1321-1325.

37 Qiu J, Guo X, Chen ZM, He L, Sonnenberg GF, Artis D et al. Group 3 innate lymphoid cells inhibit T-cell-mediated intestinal inflammation through aryl hydrocarbon receptor signaling and regulation of microflora. Immunity 2013; 39: 386-399.

38 Kruglov AA, Grivennikov SI, Kuprash DV, Winsauer C, Prepens S, Seleznik GM et al. Nonredundant function of soluble LTalpha3 
produced by innate lymphoid cells in intestinal homeostasis. Science 2013; 342: 1243-1246.

39 Gury-BenAri M, Thaiss CA, Serafini N, Winter DR, Giladi A, LaraAstiaso $\mathrm{D}$ et al. The spectrum and regulatory landscape of intestinal innate lymphoid cells are shaped by the microbiome. Cell 2016; 166: 1231-1246.

40 Kinnebrew MA, Buffie CG, Diehl GE, Zenewicz LA, Leiner I, Hohl TM et al. Interleukin 23 production by intestinal CD103(+)CD11b(+) dendritic cells in response to bacterial flagellin enhances mucosal innate immune defense. Immunity 2012; 36: 276-287.

41 Mortha A, Chudnovskiy A, Hashimoto D, Bogunovic M, Spencer SP, Belkaid $Y$ et al. Microbiota-dependent crosstalk between macrophages and ILC3 promotes intestinal homeostasis. Science 2014; 343: 1249288.

42 Longman RS, Diehl GE, Victorio DA, Huh JR, Galan C, Miraldi ER et al. $\mathrm{CX}(3) \mathrm{CR} 1(+)$ mononuclear phagocytes support colitisassociated innate lymphoid cell production of IL-22. J Exp Med 2014; 211: 1571-1583.

43 Hepworth MR, Fung TC, Masur SH, Kelsen JR, McConnell FM, Dubrot $\mathrm{J}$ et al. Immune tolerance. Group 3 innate lymphoid cells mediate intestinal selection of commensal bacteria-specific CD4(+) T cells. Science 2015; 348: 1031-1035.

44 Duan J, Chung H, Troy E, Kasper DL. Microbial colonization drives expansion of IL-1 receptor 1-expressing and IL-17-producing gamma/ delta T cells. Cell Host Microbe 2010; 7: 140-150.

45 Li F, Hao X, Chen Y, Bai L, Gao X, Lian Z et al. The microbiota maintain homeostasis of liver-resident gammadeltaT-17 cells in a lipid antigen/CD1d-dependent manner. Nat Commun 2017; 7: 13839.

46 Olszak T, An D, Zeissig S, Vera MP, Richter J, Franke A et al. Microbial exposure during early life has persistent effects on natural killer T cell function. Science 2012; 336: 489-493.

47 An D, Oh SF, Olszak T, Neves JF, Avci FY, Erturk-Hasdemir D et al. Sphingolipids from a symbiotic microbe regulate homeostasis of host intestinal natural killer T cells. Cell 2014; 156: 123-133.

48 Mattner J, Savage PB, Leung P, Oertelt SS, Wang V, Trivedi $O$ et al. Liver autoimmunity triggered by microbial activation of natural killer T cells. Cell Host Microbe 2008; 3: 304-315.

49 Treiner E, Duban L, Bahram S, Radosavljevic M, Wanner V, Tilloy F et al. Selection of evolutionarily conserved mucosal-associated invariant T cells by MR1. Nature 2003; 422: 164-169.

50 Jeffery $\mathrm{HC}$, van Wilgenburg B, Kurioka A, Parekh K, Stirling K, Roberts $S$ et al. Biliary epithelium and liver $B$ cells exposed to bacteria activate intrahepatic MAIT cells through MR1. J Hepatol 2016; 64: 1118-1127.

51 Fagarasan S, Kawamoto S, Kanagawa O, Suzuki K. Adaptive immune regulation in the gut: $\mathrm{T}$ cell-dependent and $\mathrm{T}$ cell-independent IgA synthesis. Annu Rev Immunol 2010; 28: 243-273.

52 Kunisawa J, Kiyono H. Alcaligenes is commensal bacteria habituating in the gut-associated lymphoid tissue for the regulation of intestinal IgA responses. Front Immunol 2012; 3: 65.

53 Lecuyer E, Rakotobe S, Lengline-Garnier H, Lebreton C, Picard M, Juste $C$ et al. Segmented filamentous bacterium uses secondary and tertiary lymphoid tissues to induce gut IgA and specific T helper 17 cell responses. Immunity 2014; 40: 608-620.

54 Moon C, Baldridge MT, Wallace MA, Burnham CA, Virgin HW, Stappenbeck TS. Vertically transmitted faecal IgA levels determine extra-chromosomal phenotypic variation. Nature 2015; 521: 90-93.

55 Cullender TC, Chassaing B, Janzon A, Kumar K, Muller CE, Werner JJ et al. Innate and adaptive immunity interact to quench microbiome flagellar motility in the gut. Cell Host Microbe 2013; 14: 571-581.

56 Palm NW, de Zoete MR, Cullen TW, Barry NA, Stefanowski J, Hao L et al. Immunoglobulin A coating identifies colitogenic bacteria in inflammatory bowel disease. Cell 2014; 158: 1000-1010.

57 Viladomiu M, Kivolowitz C, Abdulhamid A, Dogan B, Victorio D, Castellanos JG et al. IgA-coated E. coli enriched in Crohn's disease spondyloarthritis promote TH17-dependent inflammation. Sci Trans/ Med 2017; 9: 376

58 Fransen F, Zagato E, Mazzini E, Fosso B, Manzari C, El Aidy S et al. $\mathrm{BALB} / \mathrm{C}$ and $\mathrm{C} 57 \mathrm{BL} / 6$ mice differ in polyreactive IgA abundance, which impacts the generation of antigen-specific IgA and microbiota diversity. Immunity 2015; 43: 527-540.
59 Kawamoto S, Tran TH, Maruya M, Suzuki K, Doi Y, Tsutsui Y et al. The inhibitory receptor PD-1 regulates IgA selection and bacterial composition in the gut. Science 2012; 336: 485-489.

60 Kawamoto S, Maruya M, Kato LM, Suda W, Atarashi K, Doi Y et al. Foxp3(+) T cells regulate immunoglobulin a selection and facilitate diversification of bacterial species responsible for immune homeostasis. Immunity 2014; 41: 152-165.

61 Gaboriau-Routhiau V, Rakotobe S, Lecuyer E, Mulder I, Lan A, Bridonneau $\mathrm{C}$ et al. The key role of segmented filamentous bacteria in the coordinated maturation of gut helper $\mathrm{T}$ cell responses. Immunity 2009; 31: 677-689.

62 Lee YK, Menezes JS, Umesaki Y, Mazmanian SK. Proinflammatory T-cell responses to gut microbiota promote experimental autoimmune encephalomyelitis. Proc Natl Acad Sci USA 2011; 108(Suppl 1): 4615-4622.

63 Wu HJ, Ivanov II, Darce J, Hattori K, Shima T, Umesaki Y et al. Gutresiding segmented filamentous bacteria drive autoimmune arthritis via T helper 17 cells. Immunity 2010; 32: 815-827.

64 Van Praet JT, Donovan E, Vanassche I, Drennan MB, Windels F, Dendooven A et al. Commensal microbiota influence systemic autoimmune responses. Embo J 2015; 34: 466-474.

65 Yang Y, Torchinsky MB, Gobert M, Xiong H, Xu M, Linehan JL et al. Focused specificity of intestinal TH17 cells towards commensal bacterial antigens. Nature 2014; 510: 152-156.

66 Goto Y, Panea C, Nakato G, Cebula A, Lee C, Diez MG et al. Segmented filamentous bacteria antigens presented by intestinal dendritic cells drive mucosal Th17 cell differentiation. Immunity 2014; 40: 594-607.

67 Sano T, Huang W, Hall JA, Yang Y, Chen A, Gavzy SJ et al. An IL-23R/IL-22 circuit regulates epithelial serum amyloid $A$ to promote local effector Th17 responses. Cell 2015; 163: 381-393.

68 Panea C, Farkas AM, Goto Y, Abdollahi-Roodsaz S, Lee C, Koscso B et al. Intestinal monocyte-derived macrophages control commensalspecific Th17 responses. Cell Rep 2015; 12: 1314-1324.

69 Tan TG, Sefik E, Geva-Zatorsky N, Kua L, Naskar D, Teng F et al. Identifying species of symbiont bacteria from the human gut that, alone, can induce intestinal Th17 cells in mice. Proc Natl Acad Sci USA 2016; 113: E8141-E8150.

70 Wilck N, Matus MG, Kearney SM, Olesen SW, Forslund K, Bartolomaeus $\mathrm{H}$ et al. Salt-responsive gut commensal modulates TH17 axis and disease. Nature 2017; 551: 585-589.

71 Tanoue T, Atarashi K, Honda K. Development and maintenance of intestinal regulatory T cells. Nat Rev Immunol 2016; 16: 295-309.

72 Mazmanian SK, Liu CH, Tzianabos AO, Kasper DL. An immunomodulatory molecule of symbiotic bacteria directs maturation of the host immune system. Cell 2005; 122: 107-118.

73 Round JL, Mazmanian SK. Inducible Foxp3+ regulatory T-cell development by a commensal bacterium of the intestinal microbiota. Proc Natl Acad Sci USA 2010; 107: 12204-12209.

74 Telesford KM, Yan W, Ochoa-Reparaz J, Pant A, Kircher C, Christy MA et al. A commensal symbiotic factor derived from Bacteroides fragilis promotes human CD39(+)Foxp3(+) T cells and Treg function. Gut Microbes 2015; 6: 234-242.

75 Chu H, Khosravi A, Kusumawardhani IP, Kwon AH, Vasconcelos AC, Cunha LD et al. Gene-microbiota interactions contribute to the pathogenesis of inflammatory bowel disease. Science 2016; 352: $1116-1120$

76 Wang Y, Telesford KM, Ochoa-Reparaz J, Haque-Begum S, Christy M, Kasper EJ et al. An intestinal commensal symbiosis factor controls neuroinflammation via TLR2-mediated CD39 signalling. Nat Commun 2014; 5: 4432.

77 Atarashi K, Tanoue T, Oshima K, Suda W, Nagano Y, Nishikawa H et al. Treg induction by a rationally selected mixture of Clostridia strains from the human microbiota. Nature 2013; 500: 232-236.

78 Lathrop SK, Bloom SM, Rao SM, Nutsch K, Lio CW, Santacruz N et al. Peripheral education of the immune system by colonic commensal microbiota. Nature 2011; 478: 250-254.

79 Ohnmacht C, Park JH, Cording S, Wing JB, Atarashi K, Obata Y et al. Mucosal immunology: the microbiota regulates type 2 immunity through RORgammat(+) T cells. . Science 2015; 349: 989-993.

80 Sefik E, Geva-Zatorsky N, Oh S, Konnikova L, Zemmour D, McGuire $\mathrm{AM}$ et al. Mucosal immunology: individual intestinal symbionts 
induce a distinct population of RORgamma(+) regulatory $T$ cells. Science 2015; 349: 993-997.

81 Yang $\mathrm{BH}$, Hagemann S, Mamareli $\mathrm{P}$, Lauer U, Hoffmann U, Beckstette $\mathrm{M}$ et al. Foxp3(+) $\mathrm{T}$ cells expressing RORgammat represent a stable regulatory T-cell effector lineage with enhanced suppressive capacity during intestinal inflammation. Mucosal Immunol 2016; 9: 444-457.

82 Schiering C, Krausgruber T, Chomka A, Frohlich A, Adelmann K, Wohlfert EA et al. The alarmin IL-33 promotes regulatory T-cell function in the intestine. Nature 2014; 513: 564-568.

83 Jones JL, Thompson SA, Loh P, Davies JL, Tuohy OC, Curry AJ et al. Human autoimmunity after lymphocyte depletion is caused by homeostatic T-cell proliferation. Proc Natl Acad Sci USA 2013; 110: 20200-20205.

84 King C, Ilic A, Koelsch K, Sarvetnick N. Homeostatic expansion of $T$ cells during immune insufficiency generates autoimmunity. Cell 2004; 117: 265-277.

85 Feng T, Wang L, Schoeb TR, Elson CO, Cong Y. Microbiota innate stimulation is a prerequisite for $T$ cell spontaneous proliferation and induction of experimental colitis. J Exp Med 2010; 207: 1321-1332.

86 Cording S, Fleissner D, Heimesaat MM, Bereswill S, Loddenkemper $\mathrm{C}$, Uematsu $\mathrm{S}$ et al. Commensal microbiota drive proliferation of conventional and Foxp3(+) regulatory CD4(+) T cells in mesenteric lymph nodes and Peyer's patches. Eur J Microbiol Immunol 2013; 3: $1-10$.

87 Eri T, Kawahata K, Kanzaki T, Imamura M, Michishita K, Akahira L et al. Intestinal microbiota link lymphopenia to murine autoimmunity via PD-1(+)CXCR5(-/dim) B-helper T cell induction. Sci Rep 2017; 7: 46037.

88 Chen B, Sun L, Zhang X. Integration of microbiome and epigenome to decipher the pathogenesis of autoimmune diseases. J Autoimmun 2017; 83: 31-42.

89 Sugiyama D, Nishimura K, Tamaki K, Tsuji G, Nakazawa T, Morinobu A et al. Impact of smoking as a risk factor for developing rheumatoid arthritis: a meta-analysis of observational studies. Ann Rheum Dis 2010; 69: 70-81.

90 Abdollahi-Roodsaz S, Joosten LA, Koenders MI, Devesa I, Roelofs MF, Radstake TR et al. Stimulation of TLR2 and TLR4 differentially skews the balance of $\mathrm{T}$ cells in a mouse model of arthritis. J Clin Invest 2008; 118: 205-216.

91 Messemaker TC, Huizinga TW, Kurreeman F. Immunogenetics of rheumatoid arthritis: understanding functional implications. J Autoimmun 2015; 64: 74-81.

92 Rosser EC, Oleinika K, Tonon S, Doyle R, Bosma A, Carter NA et al. Regulatory $B$ cells are induced by gut microbiota-driven interleukin1 beta and interleukin-6 production. Nat Med 2014; 20: 1334-1339.

93 Bradley CP, Teng F, Felix KM, Sano T, Naskar D, Block KE et al. Segmented filamentous bacteria provoke lung autoimmunity by inducing gut-lung axis Th17 cells expressing dual TCRs. Cell Host Microbe 2017; 22: 697-704.e694.

94 Scher JU, Sczesnak A, Longman RS, Segata N, Ubeda C, Bielski C et al. Expansion of intestinal Prevotella copri correlates with enhanced susceptibility to arthritis. Elife 2013; 2: e01202.

95 Pianta A, Arvikar S, Strle K, Drouin EE, Wang Q, Costello CE et al. Evidence of the immune relevance of Prevotella copri, a gut microbe, in patients with rheumatoid arthritis. Arthritis Rheumatol 2017; 69: 964-975.

96 Pianta A, Arvikar SL, Strle K, Drouin EE, Wang Q, Costello CE et al. Two rheumatoid arthritis-specific autoantigens correlate microbial immunity with autoimmune responses in joints. J Clin Invest 2017; 127: 2946-2956.

97 Zhang X, Zhang D, Jia H, Feng Q, Wang D, Liang D et al. The oral and gut microbiomes are perturbed in rheumatoid arthritis and partly normalized after treatment. Nat Med 2015; 21: 895-905.

98 Terao C, Asai K, Hashimoto M, Yamazaki T, Ohmura K, Yamaguchi A et al. Significant association of periodontal disease with anticitrullinated peptide antibody in a Japanese healthy populationThe Nagahama study. J Autoimmun 2015; 59: 85-90.

99 de Aquino SG, Abdollahi-Roodsaz S, Koenders MI, van de Loo FA, Pruijn GJ, Marijnissen RJ et al. Periodontal pathogens directly promote autoimmune experimental arthritis by inducing a TLR2and IL-1-driven Th17 response. J Immunol 2014; 192: 4103-4111.
100 Montgomery AB, Kopec J, Shrestha L, Thezenas ML, Burgess-Brown NA, Fischer R et al. Crystal structure of Porphyromonas gingivalis peptidylarginine deiminase: implications for autoimmunity in rheumatoid arthritis. Ann Rheum Dis 2016; 75: 1255-1261.

101 Konig MF, Abusleme L, Reinholdt J, Palmer RJ, Teles RP, Sampson $\mathrm{K}$ et al. Aggregatibacter actinomycetemcomitans-induced hypercitrullination links periodontal infection to autoimmunity in rheumatoid arthritis. Sci Trans/ Med 2016; 8: 369ra176.

102 Achenbach P, Bonifacio E, Koczwara K, Ziegler AG. Natural history of type 1 diabetes. Diabetes 2005; 54(Suppl 2): S25-S31.

103 Kostic AD, Gevers D, Siljander H, Vatanen T, Hyotylainen T, Hamalainen AM et al. The dynamics of the human infant gut microbiome in development and in progression toward type 1 diabetes. Cell Host Microbe 2015; 17: 260-273.

104 Brugman S, Klatter FA, Visser JT, Wildeboer-Veloo AC, Harmsen HJ, Rozing $\mathrm{J}$ et al. Antibiotic treatment partially protects against type 1 diabetes in the Bio-Breeding diabetes-prone rat. Is the gut flora involved in the development of type 1 diabetes? Diabetologia 2006; 49: 2105-2108.

105 Brown K, Godovannyi A, Ma C, Zhang Y, Ahmadi-Vand Z, Dai C et al. Prolonged antibiotic treatment induces a diabetogenic intestinal microbiome that accelerates diabetes in NOD mice. Isme j 2016; 10: 321-332.

106 Harrison LC, Honeyman MC, Morahan G, Wentworth JM, Elkassaby S, Colman PG et al. Type 1 diabetes: lessons for other autoimmune diseases? J Autoimmun 2008; 31: 306-310.

107 Peng J, Narasimhan S, Marchesi JR, Benson A, Wong FS, Wen L. Long term effect of gut microbiota transfer on diabetes development. J Autoimmun 2014; 53: 85-94.

108 Tai N, Peng J, Liu F, Gulden E, Hu Y, Zhang X et al. Microbial antigen mimics activate diabetogenic CD8 T cells in NOD mice. J Exp Med 2016; 213: 2129-2146.

109 Silverman M, Kua L, Tanca A, Pala M, Palomba A, Tanes C et al. Protective major histocompatibility complex allele prevents type 1 diabetes by shaping the intestinal microbiota early in ontogeny. Proc Natl Acad Sci USA 2017; 114: 9671-9676.

110 Marino E, Richards JL, McLeod KH, Stanley D, Yap YA, Knight J et al. Gut microbial metabolites limit the frequency of autoimmune T cells and protect against type 1 diabetes. Nat Immunol 2017; 18: 552-562.

111 Hanninen A, Toivonen R, Poysti S, Belzer C, Plovier H, Ouwerkerk JP et al. Akkermansia muciniphila induces gut microbiota remodelling and controls islet autoimmunity in NOD mice. Gut 2017; pii: gutjnl2017-314508, doi:10.1136/gutjnl-2017-314508.

112 de Goffau MC, Luopajarvi K, Knip M, Ilonen J, Ruohtula T, Harkonen $T$ et al. Fecal microbiota composition differs between children with beta-cell autoimmunity and those without. Diabetes 2013; 62: 1238-1244.

113 Giongo A, Gano KA, Crabb DB, Mukherjee N, Novelo LL, Casella G et al. Toward defining the autoimmune microbiome for type 1 diabetes. ISME J 2011; 5: 82-91.

114 Markle JG, Frank DN, Mortin-Toth S, Robertson CE, Feazel LM, RolleKampczyk $U$ et al. Sex differences in the gut microbiome drive hormone-dependent regulation of autoimmunity. Science 2013; 339: 1084-1088.

115 Yurkovetskiy L, Burrows M, Khan AA, Graham L, Volchkov P, Becker L et al. Gender bias in autoimmunity is influenced by microbiota. Immunity 2013; 39: 400-412.

116 Selmi C, Barin JG, Rose NR. Current trends in autoimmunity and the nervous system. J Autoimmun 2016; 75: 20-29.

117 Berer K, Mues M, Koutrolos M, Rasbi ZA, Boziki M, Johner C et al. Commensal microbiota and myelin autoantigen cooperate to trigger autoimmune demyelination. Nature 2011; 479: 538-541.

118 Wang Y, Begum-Haque S, Telesford KM, Ochoa-Reparaz J, Christy M, Kasper EJ et al. A commensal bacterial product elicits and modulates migratory capacity of CD39(+) CD4 T regulatory subsets in the suppression of neuroinflammation. Gut Microbes 2014; 5: 552-561.

119 Rothhammer V, Mascanfroni ID, Bunse L, Takenaka MC, Kenison JE, Mayo $L$ et al. Type I interferons and microbial metabolites of tryptophan modulate astrocyte activity and central nervous system inflammation via the aryl hydrocarbon receptor. Nat Med 2016; 22: 586-597. 
120 Jangi S, Gandhi R, Cox LM, Li N, von Glehn F, Yan R et al. Alterations of the human gut microbiome in multiple sclerosis. Nat Commun 2016; 7: 12015.

121 Chen J, Chia N, Kalari KR, Yao JZ, Novotna M, Soldan MM et al. Multiple sclerosis patients have a distinct gut microbiota compared to healthy controls. Sci Rep 2016; 6: 28484.

122 Berer K, Gerdes LA, Cekanaviciute E, Jia X, Xiao L, Xia Z et al. Gut microbiota from multiple sclerosis patients enables spontaneous autoimmune encephalomyelitis in mice. Proc Natl Acad Sci USA 2017; 114: 10719-10724.

123 Cekanaviciute E, Yoo BB, Runia TF, Debelius JW, Singh S, Nelson CA et al. Gut bacteria from multiple sclerosis patients modulate human T cells and exacerbate symptoms in mouse models. Proc Natl Acad Sci USA 2017; 114: 10713-10718.

124 Wiest R, Albillos A, Trauner M, Bajaj J, Jalan R. 'Targeting the gut-liver axis in liver disease'. J Hepatol 2017; 67: 1084-1103.

125 Trivedi PJ, Adams DH. Mucosal immunity in liver autoimmunity: a comprehensive review. J Autoimmun 2013; 46: 97-111.

126 Henao-Mejia J, Elinav E, Thaiss CA, Licona-Limon P, Flavell RA. Role of the intestinal microbiome in liver disease. J Autoimmun 2013; 46: 66-73.

127 Balmer ML, Slack E, de Gottardi A, Lawson MA, Hapfelmeier S, Miele $\mathrm{L}$ et al. The liver may act as a firewall mediating mutualism between the host and its gut commensal microbiota. Sci Trans/ Med 2014; $6237 r a 266$.

128 Spadoni I, Zagato E, Bertocchi A, Paolinelli R, Hot E, Di Sabatino A et al. A gut-vascular barrier controls the systemic dissemination of bacteria. Science 2015; 350: 830-834

129 Henao-Mejia J, Elinav E, Jin C, Hao L, Mehal WZ, Strowig T et al. Inflammasome-mediated dysbiosis regulates progression of NAFLD and obesity. Nature 2012; 482: 179-185.

130 Schneider KM, Bieghs V, Heymann F, Hu W, Dreymueller D, Liao L et al. CX3CR 1 is a gatekeeper for intestinal barrier integrity in mice: Limiting steatohepatitis by maintaining intestinal homeostasis. Hepatology 2015; 62: 1405-1416.

131 Haruta I, Kikuchi K, Hashimoto E, Nakamura M, Miyakawa H, Hirota $\mathrm{K}$ et al. Long-term bacterial exposure can trigger nonsuppurative destructive cholangitis associated with multifocal epithelial inflammation. Lab Invest 2010; 90: 577-588.

132 Terjung B, Sohne J, Lechtenberg B, Gottwein J, Muennich M, Herzog $\checkmark$ et al. p-ANCAs in autoimmune liver disorders recognise human beta-tubulin isotype 5 and cross-react with microbial protein FtsZ. Gut 2010; 59: 808-816.

133 Melum E, Franke A, Schramm C, Weismuller TJ, Gotthardt DN, Offner FA et al. Genome-wide association analysis in primary sclerosing cholangitis identifies two non-HLA susceptibility loci. Nat Genet 2011; 43: 17-19.

134 Rupp C, Friedrich K, Folseraas T, Wannhoff A, Bode KA, Weiss KH et al. Fut2 genotype is a risk factor for dominant stenosis and biliary candida infections in primary sclerosing cholangitis. Aliment Pharmacol Ther 2014; 39: 873-882.

135 Janse $M$, Lamberts LE, Franke L, Raychaudhuri S, Ellinghaus E, Muri Boberg $\mathrm{K}$ et al. Three ulcerative colitis susceptibility loci are associated with primary sclerosing cholangitis and indicate a role for IL2, REL, and CARD9. Hepatology 2011; 53: 1977-1985.

$136 \mathrm{Li} \mathrm{X}$, Shen J, Ran Z. Crosstalk between the gut and the liver via susceptibility loci: novel advances in inflammatory bowel disease and autoimmune liver disease. Clin Immunol 2017; 175: $115-123$.

137 Wannhoff A, Rupp C, Friedrich K, Brune M, Knierim J, Flechtenmacher $\mathrm{C}$ et al. Inflammation but not biliary obstruction is associated with carbohydrate antigen 19-9 levels in patients with primary sclerosing cholangitis. Clin Gastroenterol Hepatol 2015; 13: 2372-2379.

138 Eksteen B, Grant AJ, Miles A, Curbishley SM, Lalor PF, Hubscher SG et al. Hepatic endothelial CCL25 mediates the recruitment of CCR9+ gut-homing lymphocytes to the liver in primary sclerosing cholangitis. J Exp Med 2004; 200: 1511-1517.

139 Trivedi PJ, Bruns T, Ward S, Mai M, Schmidt C, Hirschfield GM et al. Intestinal CCL25 expression is increased in colitis and correlates with inflammatory activity. J Autoimmun 2016; 68: 98-104.

140 Seidel D, Eickmeier I, Kuhl AA, Hamann A, Loddenkemper C, Schott E. CD8 T cells primed in the gut-associated lymphoid tissue induce immune-mediated cholangitis in mice. Hepatology 2014; 59: 601-611.

141 Henriksen EK, Jorgensen KK, Kaveh F, Holm K, Hamm D, Olweus J et al. Gut and liver T-cells of common clonal origin in primary sclerosing cholangitis-inflammatory bowel disease. J Hepatol 2017; 66: $116-122$.

142 Moro-Sibilot L, Blanc P, Taillardet M, Bardel E, Couillault C, Boschetti $\mathrm{G}$ et al. Mouse and human liver contain immunoglobulin A-secreting cells originating from Peyer's patches and directed against intestinal antigens. Gastroenterology 2016; 151: 311-323.

143 Trivedi PJ, Tickle J, Vesterhus MN, Eddowes PJ, Bruns T, Vainio J et al. Vascular adhesion protein-1 is elevated in primary sclerosing cholangitis, is predictive of clinical outcome and facilitates recruitment of gut-tropic lymphocytes to liver in a substratedependent manner. Gut 2017; 67: 1084-1103.

$144 \mathrm{Li} \mathrm{Y,} \mathrm{Tang} \mathrm{R,} \mathrm{Leung} \mathrm{PSC,} \mathrm{Gershwin} \mathrm{ME,} \mathrm{Ma} \mathrm{X.} \mathrm{Bile} \mathrm{acids} \mathrm{and}$ intestinal microbiota in autoimmune cholestatic liver diseases. Autoimmun Rev 2017; 16: 885-896.

145 Sayin SI, Wahlstrom A, Felin J, Jantti S, Marschall HU, Bamberg K et al. Gut microbiota regulates bile acid metabolism by reducing the levels of tauro-beta-muricholic acid, a naturally occurring FXR antagonist. Cell Metab 2013; 17: 225-235.

146 Li F, Jiang C, Krausz KW, Li Y, Albert I, Hao H et al. Microbiome remodelling leads to inhibition of intestinal farnesoid $X$ receptor signalling and decreased obesity. Nat Commun 2013; 4: 2384.

147 Jiang C, Xie C, Li F, Zhang L, Nichols RG, Krausz KW et al. Intestinal farnesoid $X$ receptor signaling promotes nonalcoholic fatty liver disease. J Clin Invest 2015; 125: 386-402.

148 Wahlstrom A, Sayin SI, Marschall HU, Backhed F. Intestinal crosstalk between bile acids and microbiota and its impact on host metabolism. Cell Metab 2016; 24: 41-50.

149 Islam KB, Fukiya S, Hagio M, Fujii N, Ishizuka S, Ooka T et al. Bile acid is a host factor that regulates the composition of the cecal microbiota in rats. Gastroenterology 2011; 141: 1773-1781.

150 Ubeda M, Lario M, Munoz L, Borrero MJ, Rodriguez-Serrano M, Sanchez-Diaz AM et al. Obeticholic acid reduces bacterial translocation and inhibits intestinal inflammation in cirrhotic rats. $J$ Hepatol 2016; 64: 1049-1057.

151 Parseus A, Sommer N, Sommer F, Caesar R, Molinaro A, Stahlman M et al. Microbiota-induced obesity requires farnesoid $\mathrm{X}$ receptor. Gut 2017; 66: 429-437.

152 Tang R, Wei Y, Li Y, Chen W, Chen H, Wang Q et al. Gut microbial profile is altered in primary biliary cholangitis and partially restored after UDCA therapy. Gut 2017; 67: 534-541.

153 Lv LX, Fang DQ, Shi D, Chen DY, Yan R, Zhu YX et al. Alterations and correlations of the gut microbiome, metabolism and immunity in patients with primary biliary cirrhosis. Environ Microbiol 2016; 18 : 2272-2286.

$154 \mathrm{Hov}$ JR, Kummen M. Intestinal microbiota in primary sclerosing cholangitis. Curr Opin Gastroenterol 2017; 33: 85-92.

155 Torres J, Bao X, Goel A, Colombel JF, Pekow J, Jabri B et al. The features of mucosa-associated microbiota in primary sclerosing cholangitis. Aliment Pharmacol Ther 2016; 43: 790-801.

156 Quraishi MN, Sergeant M, Kay G, Iqbal T, Chan J, Constantinidou C et al. The gut-adherent microbiota of PSC-IBD is distinct to that of IBD. Gut 2017; 66: 386-388.

157 Rossen NG, Fuentes S, Boonstra K, D'Haens GR, Heilig HG, Zoetendal EG et al. The mucosa-associated microbiota of PSC patients is characterized by low diversity and low abundance of uncultured Clostridiales II. J Crohns Colitis 2015; 9: 342-348.

158 Kevans D, Tyler AD, Holm K, Jorgensen KK, Vatn MH, Karlsen TH et al. Characterization of intestinal microbiota in ulcerative colitis patients with and without primary sclerosing cholangitis. J Crohns Colitis 2016; 10: 330-337.

159 Ruhlemann MC, Heinsen FA, Zenouzi R, Lieb W, Franke A, Schramm C. Faecal microbiota profiles as diagnostic biomarkers in primary sclerosing cholangitis. Gut 2017; 66: 753-754.

160 Sabino J, Vieira-Silva S, Machiels K, Joossens M, Falony G, Ballet V et al. Primary sclerosing cholangitis is characterised by intestinal dysbiosis independent from IBD. Gut 2016; 65: 1681-1689.

161 Kummen M, Holm K, Anmarkrud JA, Nygard S, Vesterhus M, Hoivik $\mathrm{ML}$ et al. The gut microbial profile in patients with primary sclerosing cholangitis is distinct from patients with ulcerative colitis 
without biliary disease and healthy controls. Gut 2016; 66: 611-619.

162 Iwasawa K, Suda W, Tsunoda T, Oikawa-Kawamoto M, Umetsu S, Inui $\mathrm{A}$ et al. Characterisation of the faecal microbiota in Japanese patients with paediatric-onset primary sclerosing cholangitis. Gut 2016; 66: 1344-1346.

163 Schrumpf E, Kummen M, Valestrand L, Greiner TU, Holm K, Arulampalam $\mathrm{V}$ et al. The gut microbiota contributes to a mouse model of spontaneous bile duct inflammation. J Hepatol 2017; 66: 382-389.

164 Tabibian JH, O'Hara SP, Trussoni CE, Tietz PS, Splinter PL, Mounajjed $\mathrm{T}$ et al. Absence of the intestinal microbiota exacerbates hepatobiliary disease in a murine model of primary sclerosing cholangitis. Hepatology 2016; 63: 185-196.

165 Blander JM, Longman RS, Iliev ID, Sonnenberg GF, Artis D. Regulation of inflammation by microbiota interactions with the host. Nat Immunol 2017; 18: 851-860.

166 Cohen NA, Maharshak N. Novel indications for fecal microbial transplantation: update and review of the literature. Dig Dis SCi 2017; 62: 1131-1145.

167 de Oliveira GLV, Leite AZ, Higuchi BS, Gonzaga MI, Mariano VS. Intestinal dysbiosis and probiotic applications in autoimmune diseases. Immunology 2017; 152: 1-12.

168 Hugenholtz F, de Vos WM. Mouse models for human intestinal microbiota research: a critical evaluation. Cell Mol Life Sci 2017; 75: 149-160.

169 Yadav SK, Boppana S, Ito N, Mindur JE, Mathay MT, Patel A et al. Gut dysbiosis breaks immunological tolerance toward the central nervous system during young adulthood. Proc Natl Acad Sci USA 2017; 114: E9318-E9327.

170 Uusitalo U, Liu X, Yang J, Aronsson CA, Hummel S, Butterworth M et al. Association of early exposure of probiotics and islet autoimmunity in the TEDDY Study. JAMA Pediatr 2016; 170: 20-28.

$171 \mathrm{Kong} \mathrm{HH}$, Segre JA. The molecular revolution in cutaneous biology: investigating the skin microbiome. J Invest Dermatol 2017; 137: e119-e122.

172 Yan D, Issa N, Afifi L, Jeon C, Chang HW, Liao W. The role of the skin and gut microbiome in psoriatic disease. J Curr Dermatol Rep 2017; 6: 94-103.

This work is licensed under a Creative Commons Attribution 4.0 International License. The images or other third party material in this article are included in the article's Creative Commons license, unless indicated otherwise in the credit line; if the material is not included under the Creative Commons license, users will need to obtain permission from the license holder to reproduce the material. To view a copy of this license, visit http:// creativecommons.org/licenses/by/4.0/

C) The Author(s) 2018 